Article

\title{
Innovative Culturomic Approaches and Predictive Functional Metagenomic Analysis: The Isolation of Hydrocarbonoclastic Bacteria with Plant Growth Promoting Capacity
}

\author{
Ilaria Chicca $^{1}$, Simone Becarelli ${ }^{1,2} \mathbb{D}$, Giacomo Bernabei ${ }^{1} \mathbb{D}$, Giovanna Siracusa ${ }^{1}$ and Simona Di Gregorio ${ }^{1, * \mathbb{D}}$ \\ 1 Department of Biology, University of Pisa, Via Luca Ghini, 13, 56126 Pisa, Italy; \\ ilaria.chicca@biologia.unipi.it (I.C.); simone.becarelli@biologia.unipi.it (S.B.); \\ g.bernabei1@studenti.unipi.it (G.B.); giovanna.siracusa@biologia.unipi.it (G.S.) \\ 2 BD Biodigressioni srl, Lungarno Mediceo 40, 56126 Pisa, Italy \\ * Correspondence: simona.digregorio@unipi.it
}

check for updates

Citation: Chicca, I.; Becarelli, S.; Bernabei, G.; Siracusa, G.; Di Gregorio, S. Innovative Culturomic Approaches and Predictive Functional Metagenomic Analysis: The Isolation of Hydrocarbonoclastic Bacteria with Plant Growth Promoting Capacity. Water 2022, 14, 142. https://doi.org/10.3390/ w14020142

Academic Editor: Xuwang Zhang

Received: 4 December 2021

Accepted: 1 January 2022

Published: 6 January 2022

Publisher's Note: MDPI stays neutral with regard to jurisdictional claims in published maps and institutional affiliations.

Copyright: (c) 2022 by the authors. Licensee MDPI, Basel, Switzerland. This article is an open access article distributed under the terms and conditions of the Creative Commons Attribution (CC BY) license (https:// creativecommons.org/licenses/by/ $4.0 /)$.

\begin{abstract}
Innovative culturomic approaches were adopted to isolate hydrocarbonoclastic bacteria capable of degrading diesel oil, bitumen and a selection of polycyclic aromatic hydrocarbons (PAH), e.g., pyrene, anthracene, and dibenzothiophene, from a soil historically contaminated by total petroleum hydrocarbons $(\mathrm{TPH})(10,347 \pm 98 \mathrm{mg} \mathrm{TPH} / \mathrm{kg})$. The culturomic approach focussed on the isolation of saprophytic microorganisms and specialist bacteria utilising the contaminants as sole carbon sources. Bacterial isolates belonging to Pseudomonas, Arthrobacter, Achromobacter, Bacillus, Lysinibacillus, Microbacterium sps. were isolated for their capacity to utilise diesel oil, bitumen, pyrene, anthracene, dibenzothiphene, and their mixture as sole carbon sources. Pseudomonas, Arthrobacter, Achromobacter and Microbacterium sps. showed plant growth promoting activity, producing indole3-acetic acid and expressing 1-aminocyclopropane-1-carboxylic acid (ACC) deaminase activity. In parallel to the culturomic approach, in the microbial community of interest, bacterial community metabarcoding and predictive functional metagenomic analysis were adopted to confirm the potentiality of the isolates in terms of their functional representativeness. The combination of isolation and molecular approaches for the characterisation of a TPH contaminated soil microbial community is proposed as an instrument for the construction of an artificial hydrocarbonoclastic microbiota for environmental restoration.
\end{abstract}

Keywords: culturomic; microbiota; predictive functional metagenomic analysis; Pseudomonas; Arthrobacter; Achromobacter; Bacillus; Lysinibacillus; Microbacterium; 1-aminocyclopropane-1-carboxylic acid (ACC) deaminase; indole-3-acetic acid

\section{Introduction}

In the last century, the development of chemical and petrochemical industries resulted in the production of a variety of xenobiotics, such as solvents, fuels, plastics, and other organic pollutants, which were recalcitrant to biodegradation and persistent in the environment. In Europe, Total Petroleum Hydrocarbons (TPH) have been identified as the major cause of contamination in polluted soils and sediments, and they are persistent in environmental matrices and significantly recalcitrant to biodegradation [1]. This persistence leads to the natural selection of microorganisms able to transform TPH. These microorganisms might be considered as "extremophiles", adapted to live in extreme environments, characterised by high toxicity to most living organisms. Defined as specialist species, they can utilise contaminants as sole carbon sources for growth [2].

The bio-based processes dedicated to the decontamination of environmental matrices are focussed on the isolation, characterisation, and exploitation of specialist species. However, it is worth mentioning that, it is not single strains, but microbial assemblages, with syntrophic associations, that are principally responsible for the transformation of 
xenobiotics in the environment. It is already accepted that xenobiotic degradation in a complex matrix like soil, cannot be achieved individually, but by complex community interactions, using different metabolic strategies of microorganisms adapted to the contaminants. Moreover, the biodegradation of contamination should achieve not only its transformation and eventual mineralisation [3], but also the "re-shaping" of the soil as a matrix, offering ecosystem services [4,5].

Understanding how microbial communities work cooperatively, communicate, and act to bioremediate environments, is of great interest and importance [6]. Tools that might be helpful in this investigation include both the functional analysis of metagenomes in the polluted soils and the isolation of soil microbiota, capable of utilising the contamination as a sole carbon source. Studies on the interplay of soil microorganisms during the process of TPH depletion by oxidative processes, have been tentatively approached by the interpretation of data derived by microbial metabarcoding and the predictive functional metagenomic analysis of complex microbial communities $[7,8]$. The results obtained have suggested that different stages of TPH transformation are covered by different bacterial groups, which is in accordance with the concept that complex microbiota are cooperatively responsible for the restoration of soil quality and eventually its resilience. The metabolism of saprophytic microorganisms has been shown to be of particular interest, since it is responsible for the mobilisation of organic matter. This matter, in contaminated matrices, consists mainly of the source of contamination, and saprophytic metabolism is involved in increasing its bioavailability and eventually determining the conditions for its biodegradation by specialist species [8].

Saprophytic microorganisms might be defined as a generalist species. For growth generalist species exploit a plethora of diverse carbon sources that might be present in the environment at low concentrations [2]. In contaminated environments they play a pivotal role in soil restoration, their activities ranging from xenobiotic depletion to participation in the synthesis and cycling of organic matter in the soil [8], all crucial aspects for restoring the correct basal metabolism of a resilient soil.

In this context, plant growth promoting (PGP) bacteria might also contribute to the restoration of soil quality, by their interaction with the primary producers colonising the matter e.g., plants. In fact, PGP bacteria can improve the architecture and extension of the plant root system by the production of auxins. They can also counteract the possible phytotoxic effects of polluted soil; decreasing the plant response to abiotic stresses through inhibiting ethylene production by the intervention of 1-aminocyclopropane-1carboxylate deaminase activity [9]. Their involvement in the degradation of contaminants has also been described, by both directly and indirectly, improving plant performances in phytoremediation [10].

Microbial isolates combining both xenobiotic degradation capacity and PGP potential are a smart and sustainable tool to be exploited in the planning of bio-based remediation interventions for the restoration of contaminated soils.

The scope of the present work was the evaluation of the capacity of the microbial community, colonising a historically TPH contaminated soil, to show PGP activity and to promote the oxidative transformation of the contamination. To address this scope, metabarcoding of the bacterial community and a predictive functional metagenomic analysis were adopted. In parallel, an innovative culturomic approach of bacteria capable of utilising the contamination as a sole carbon source was implemented, exploiting both consolidated strategies for the isolation of specialist species, and employing isolating strategies for generalist and Gram-positive bacterial species, described as an efficient hydrocarbonoclastic class of bacteria [11]. The recalcitrant compounds selected here for mimicking TPH contamination and exploited for the enrichment and testing of hydrocarbonoclastic bacteria, were diesel oil, bitumen and a selection of polycyclic aromatic hydrocarbons (PAH), e.g., pyrene, anthracene, and dibenzothiphene. In the site of origin of the contaminated soil, these PAHs have occasionally been quantified above the legislative limits. On the other hand, both diesel oil and bitumen contain a saturated fraction of alkanes and an 
unsaturated fraction, containing naphthenic aromatics, which consist of hydrogenated polycyclic aromatic compounds, high molecular weight phenols, carboxylic acids, and heterocyclic compounds (information provided by commercial producers). The complex composition of diesel oil and bitumen is similar to the uncharacterised complex mixture of TPH contaminated environmental matrices [12]. A total of 17 hydrocarbonoclastic bacterial strains were isolated and evaluated for their PGP capacity. Bacterial strains, combining both hydrocarbonoclastic and PGP capacities, were proposed to design a synthetic microbiota for environmental restoration.

\section{Materials and Methods}

\subsection{Contaminated Soil and Chemicals}

The contaminated soil $(10,347 \pm 98 \mathrm{mg}$ TPH$/ \mathrm{kg})$ was sampled at a decommissioned oil refinery in Trieste $\left(45^{\circ} 36^{\prime} 16.9^{\prime \prime} \mathrm{N} ; 13^{\circ} 47^{\prime} 56.4^{\prime \prime} \mathrm{E}\right)$. Three different samples of the top $20 \mathrm{~cm}$ layer were collected by a box corer inside a superficial area of $1 \mathrm{~m}^{2}$. The obtained 3 soil samples were roughly mixed before sampling the 3 soil amounts for DNA extraction. The area represented a hot spot of the site. Diesel oil was purchased from a local service station. Bitumen in xylene (POLYPRIMER) was provided by MAPEI (Milan, Italy). All the chemicals used were of analytical grade and purchased from Merck (Milan, Italy).

\subsection{Metabarcoding}

The total DNA from soil was extracted from $500 \mathrm{mg}$ of the sample using a FastPrep $24^{\mathrm{TM}}$ homogenizer and FAST DNA Spin kit for soil (MP Biomedicals), proceeding according to manufacturer's protocol. The quantity of DNA was measured using a Qubit 3.0 Fluorometer (ThermoFisher Scientific, Milan, Italy). The DNA purity and quality was determined spectrophotometrically (Biotek Powerwave Xs Microplate Spectrophotometer, Milan, Italy) by measuring absorbance at 260/280 and 260/230 nm. A total of $200 \mathrm{ng}$ of DNA was used to produce paired-end libraries and for sequencing the V4-V5 hypervariable regions of the bacterial 16S rRNA gene by using as primers, 515F forward primer ( $5^{\prime}$-GTGCCAGCMGCCG CGGTAA-3') and 907R reverse primer (5'-CCGTCAATTCCTTTGAGTTT-3'). The libraries for Illumina sequencing were prepared by Novogene using the NEBNext Ultra DNA Library Prep Kit, following the manufacturer's recommendations, and index codes were added. The library was sequenced on an Illumina platform by Novogene (Novogene Company Limited Rm.19C, Lockhart Ctr., 301-307, Lockhart Rd. Wan Chai, Hong Kong), and $250 \mathrm{bp}$ paired-end reads were generated.

\subsection{Data Analysis}

Paired-end reads were demultiplexed and trimmed by the Cutadapt plugin for Qiime2. Forward and reverse reads were assembled, quality filtered, chimera filtered and assigned to Amplicon Sequence Variants (ASVs) following the Qiime2 v.2021.2 standard pipeline. Clustering of Amplicon Sequence Variants (ASVs) was performed using the DADA2 workflow implemented in Qiime2, with classifiers trained on the V4-V5 hypervariable region extracted from the Silva 138 99\% 16S sequences database. The functional metagenomic prediction for the bacterial community was inferred using PICRUSt2 v. 2.4.1 for an unstratified and stratified metagenome contribution based on EC numbers. KEGG pathway and EC contributions were filtered from the output data of PICRUSt2 v. 2.4.1 and processed by R v. 4.1.1. The graphical output was produced by ggplot2 package v. 3.3.5 and Pheatmap v. 1.0.12.

\subsection{Isolation of Hydrocarbonoclastic Specialist Species}

Specialist bacterial species capable of utilising contaminants as sole carbon sources were isolated by incubating $2 \mathrm{~g}$ of soil in $500 \mathrm{~mL}$ of Basal Salt Medium $\left(\mathrm{Na}_{2} \mathrm{HPO}_{4} 2.2 \mathrm{~g}\right.$, $\mathrm{KH}_{2} \mathrm{PO}_{4} 0.8 \mathrm{~g}, \mathrm{NH}_{4} \mathrm{NO}_{3} 3.0 \mathrm{~g}$ per $\mathrm{L}$ of deionised water) amended with $2 \mathrm{~mL}$ of diesel oil, $2 \mathrm{~mL}$ of bitumen in xylene, $500 \mathrm{mg} / \mathrm{L}$ pyrene, $200 \mathrm{mg} / \mathrm{L}$ anthracene and $200 \mathrm{mg} / \mathrm{L}$ dibenzothiophene solubilised in diethyl ether. All the above reagents were pooled together in a sterile flask of $1.5 \mathrm{~L}$ and maintained at room temperature in a rotator at $150 \mathrm{rpm}$ for 
15 days. After 15 days, $20 \mathrm{~mL}$ of the liquid culture was inoculated into fresh medium. This was repeated for a total of three passages. At the end of the third passage, serial dilutions of the liquid culture in sterile $\mathrm{NaCl}(0.9 \%)$ solution were plated on $\mathrm{LB}$ (10 g tryptone, $5 \mathrm{~g}$ of yeast extract, $10 \mathrm{~g}$ of $\mathrm{NaCl}, 15 \mathrm{~g}$ of agar per litre of deionised water) plates to separate bacterial candidates in axenic culture.

\subsection{Isolation of Generalist Species}

Bacterial generalist species capable of utilising multiple and diverse carbon sources were isolated on an Eco-plate ${ }^{\mathrm{TM}}$, a 96-well plate which contains 31 different carbon sources (Biolog.com, accessed on 5 October 2021, Milan, Italy). To perform the isolation, $1 \mathrm{~g}$ of soil sample was resuspended in $10 \mathrm{~mL}$ of sterile saline solution $(\mathrm{NaCl}, 0.9 \% \mathrm{w} / \mathrm{v})$ was rotated at $150 \mathrm{rpm}$ for $1 \mathrm{~h}[13,14]$. The soil suspension was serially diluted to $10^{-4}$ with sterile $\mathrm{NaCl}(0.9 \%)$ solution. Then, $130 \mu \mathrm{L}$ aliquots of the diluted soil suspension were inoculated into the wells of Eco-plates ${ }^{\mathrm{TM}}$ that were incubated at $20^{\circ} \mathrm{C}$ in the dark for 14 days. The $\mathrm{OD}_{590}$ in each of the Eco-plate ${ }^{\mathrm{TM}}$ wells was measured daily on a spectrophotometer (Biotek Powerwave Xs Microplate Spectrophotometer, Milan, Italy). The 31 carbon sources ranged from amines (phenylethyl amine, putrescine), carbohydrates (D-cellobiose, $\alpha$-D-lactose, $\beta$-methyl-D glucoside, D-xylose, i-erythritol, D-mannitol, $\mathrm{N}$-acetyl-glucosamine), complex carbon sources (Tween40, Tween 80, $\alpha$-cyclodextrin, glycogen), and carboxylic acids (Dglucosamic acid, D-galactonic acid, $\gamma$-lactone, D-galacturonic acid, 2 hydroxybenzoic acid, 4-hydroxyl benzoic acid, $\gamma$-hydroxybutyric acid, itaconic acid, $\alpha$-ketobutyric acid, D-malic acid) to amino acids (L-arginine, L-asparagine, I-phenylalanine, L-serine, L-threonine, LGlycyl-L-glutamic acid). The soil suspensions corresponding to wells absorbing at $\mathrm{OD}_{590}$ were plated by serial dilution on LB plates.

\subsection{Isolation of Gram-Positive Bacteria}

Gram-positive bacteria were isolated following the protocols of [15,16]. A $20 \mathrm{~g}$ amount of soil was air and heat dried at $120^{\circ} \mathrm{C}$ for $1 \mathrm{~h}$. At the end of the treatment, $10 \mathrm{~g}$ of the dried soil was diluted in $90 \mathrm{~mL}$ of sterilised deionised water. A $10 \mathrm{~mL}$ volume of the suspension was further diluted in $90 \mathrm{~mL}$ of sterilised deionised water. Yeast extract $(6 \mathrm{~g})$ and $0.05 \mathrm{~g}$ sodium dodecyl sulphate (SDS) were amended to the suspension which was incubated at $60{ }^{\circ} \mathrm{C}$ for $20 \mathrm{~min}$. The suspension was cooled at room temperature and serially diluted in a sterile saline solution and plated on agar plates containing the chemicals shown in Table 1.

\subsection{Taxonomic Identification of the Bacterial Isolates}

All the bacterial strains isolated in axenic culture were divided into different morphotypes by visual inspection and clustered in different operational taxonomic units (OTUs) by amplified ribosomal DNA restriction analysis (ARDRA) [17]. PCR amplification of $16 \mathrm{~S}$ rDNA was performed using the 27F forward primer (5'-AG AGTTTGATCCTGGCTCAG-3') and the $1492 \mathrm{R}$ reverse primer ( $5^{\prime}$-GGTTACCTTGTTACGA CTT- $3^{\prime}$ ). PCR was performed as follows, $95^{\circ} \mathrm{C}$ for $10 \mathrm{~min}, 95^{\circ} \mathrm{C}$ for $45 \mathrm{~s}, 50{ }^{\circ} \mathrm{C}$ for $50 \mathrm{~s}, 72{ }^{\circ} \mathrm{C}$ for $2 \mathrm{~min}$ for 30 cycles, and $72{ }^{\circ} \mathrm{C}$ for $5 \mathrm{~min}$. The PCR products were purified with the purification kit Nucleospin Gel and PCR Clean-up by Macherey-Nagel GmbH \& Co. KG (Milan, Italy), following the manufacturer's instructions. The PCR product was analysed by ARDRA, performed by digesting the amplification products with Sau 3A, Alu I e Hae III (Biolabs, Milan, Italy). The PCR products corresponding to different OTUs were sequenced by the GATC service (Ebersberg, Germany).

\subsection{Capacity of the Bacterial Strains to Grow on Contaminants as Sole Carbon Sources and Their Plant Growth Promoting Activity}

Bacterial isolates corresponding to the different OTUs were tested for their capacity to grow on diesel oil, bitumen, pyrene, dibenzothiophene, or anthracene and their mixture, as sole carbon sources in a BSM liquid medium. Sterile $500 \mathrm{~mL}$ flasks containing $1500 \mathrm{~mL}$ of liquid BSM were amended with $2 \mathrm{~mL}$ of diesel oil, $2 \mathrm{~mL}$ of bitumen, $500 \mathrm{mg} / \mathrm{L}$ pyrene 
solubilized in diethyl ether, $200 \mathrm{mg} / \mathrm{L}$ anthracene solubilized in diethyl ether, $200 \mathrm{mg} / \mathrm{L}$ dibenzothiophene in diethyl ether and were inoculated with the biomass derived from $1 \mathrm{~mL}$ of bacterial suspension of each isolate grown in LB liquid medium (10 g tryptone, $5 \mathrm{~g}$ of yeast extract, $10 \mathrm{~g}$ of $\mathrm{NaCl}$ per litre of deionised water) for $48 \mathrm{~h}$. The biomasses were pelleted and washed twice with $\mathrm{NaCl}(0.9 \%)$ solution before the inoculation to remove traces of LB medium. The growth of the isolates were spectrophotometrically determined (Biotek Powerwave Xs Spectrophotometer, Milan, Italy) by comparing the turbidimetry of the inoculated flasks with non-inoculated control flasks after 15 days of incubation in the dark at $25^{\circ} \mathrm{C}$ in a rotator at $150 \mathrm{rpm}$. Bacterial isolates corresponding to the different OTUs were tested for 1-aminocyclopropane-1-carboxylic acid (ACC) deaminase activity as described in [18] and for their capacity to produce indole-3-acetic acid (IAA) as described in [19].

Table 1. Humic acid agar plates and Vitamin B solution (VB) composition.

\begin{tabular}{|c|c|}
\hline Chemical & Quantity \\
\hline Humic acid & $1.0 \mathrm{~g}$ \\
\hline $\mathrm{KCl}$ & $1.7 \mathrm{~g}$ \\
\hline $\mathrm{Na}_{2} \mathrm{HPO}_{4}$ & $0.5 \mathrm{~g}$ \\
\hline $\mathrm{MgSO}_{4}$ & $0.5 \mathrm{~g}$ \\
\hline $\mathrm{CaCO}_{3}$ & $0.02 \mathrm{~g}$ \\
\hline $\mathrm{FeSO}_{4}$ & $0.01 \mathrm{~g}$ \\
\hline Vitamin B solution & $1.0 \mathrm{~mL}$ \\
\hline Agar & $10.0 \mathrm{~g}$ \\
\hline $\mathrm{H}_{2} \mathrm{O}$ & $1 \mathrm{~L}$ \\
\hline Vitamin B solution & Quantity \\
\hline Vitamin B1 & $50 \mathrm{mg}$ \\
\hline Vitamin B2 & $50 \mathrm{mg}$ \\
\hline Niacin & $50 \mathrm{mg}$ \\
\hline Vitamin B6 & $50 \mathrm{mg}$ \\
\hline D-calcium pantothenate & $50 \mathrm{mg}$ \\
\hline Inositol & $50 \mathrm{mg}$ \\
\hline PABA & $50 \mathrm{mg}$ \\
\hline Biotin & $25 \mathrm{mg}$ \\
\hline $\mathrm{H}_{2} \mathrm{O}$ & $100 \mathrm{~mL}$ \\
\hline
\end{tabular}

\section{Results}

\subsection{Isolation of Specialist Species}

The enrichment of bacteria in the presence of a high concentration of a sole carbon source is generally considered as an approach designed to isolate specialist species that utilise that carbon source for growth. Specialist bacteria were isolated using high concentrations of bitumen, diesel oil, anthracene, pyrene and dibenzothiophene as combined carbon sources for growth in a minimal medium. A total of 18 OTUs were retrieved. After screening of the different morphotypes by ARDRA analysis, 3 out of the 18 OTUs were capable of utilising each carbon source and their mixture as sole carbon sources, and the corresponding $16 \mathrm{~S}$ rDNAs were sequenced for taxonomic identification (Table 2). 
Table 2. Specialist bacterial isolates capable of utilising different carbon sources (AQ8, EU, WhLB); Gram-positive isolates capable of utilising the different carbon sources (5+, 6+, 8+, MG+); Generalist bacterial isolates isolated using the Eco-plates ${ }^{\mathrm{TM}}$ and capable of utilising different carbon sources (Phenyl1, Phenyl4, Phenyl5, Pheny16, Pir1, Pir3, Tween80.1, Tween80.2, Ita1,Ita2). Mix: mixture of diesel oil, bitumen, anthracene, pyrene, dibenzothiophene; Anth: Anthracene; Pyr: Pyrene; Dib: dibenzothiophene; DO: diesel oil; BT: bitumen; Aux: positive for indole-3-acetic acid (IAA) production; ACCd: positive for 1-aminocyclopropane-1-carboxylic acid (ACC) deaminase activity. For each strain $(+)$ indicates that the activity was detected, (nd) that the activity was not detected.

\begin{tabular}{|c|c|c|c|c|c|c|c|c|c|c|c|c|c|c|c|c|}
\hline $\begin{array}{l}\text { OTUs } \\
\text { Name }\end{array}$ & Mix & Anth & Pyr & Dib & DO & BT & Taxonomy & $\begin{array}{l}\text { Reference } \\
\text { Taxonomy }\end{array}$ & $\begin{array}{l}\text { Homology } \\
(\%)\end{array}$ & $\begin{array}{l}\text { Phenyl } \\
\text { Ethyl Amine }\end{array}$ & $\begin{array}{l}\text { Pyruvic Acid } \\
\text { Methyl Ester }\end{array}$ & Tween 80 & $\begin{array}{l}\text { Itaconic } \\
\text { Acid }\end{array}$ & Glycogen & Aux & ACCd \\
\hline $\mathrm{AQ8}$ & + & + & + & + & + & + & Pseudomonas putida & СР022561.1 & 100 & nd & nd & nd & nd & nd & + & + \\
\hline $\mathrm{EU}$ & + & + & + & + & + & + & $\begin{array}{l}\text { Arthrobacter sp. } \\
\text { Rue61a }\end{array}$ & СР003203.1 & 99.4 & nd & nd & nd & nd & nd & + & + \\
\hline WhLB & + & + & + & + & + & + & $\begin{array}{l}\text { Arthrobacter sp. } \\
\text { StoSoilB22 }\end{array}$ & AP024652.1 & 96.5 & nd & nd & nd & nd & nd & + & + \\
\hline $5+$ & + & + & + & + & + & + & Bacillus thuringiensis & $\begin{array}{l}\text { AN: } \\
\text { MH921588 }\end{array}$ & 100 & nd & nd & nd & nd & nd & nd & nd \\
\hline $6+$ & + & + & + & + & + & + & Bacillus cereus & AN: 651600 & 97.9 & nd & nd & nd & nd & nd & + & nd \\
\hline MG+ & + & + & + & + & + & + & Bacillus thuringiensis & A.N:CP039721 & 99 & nd & nd & nd & nd & nd & nd & nd \\
\hline Phenyl1 & + & + & + & + & + & + & $\begin{array}{l}\text { Bacillus } \\
\text { weindemanni }\end{array}$ & NR_152692 & 97.00 & + & & & & & + & $\mathrm{nd}$ \\
\hline Phenyl4 & + & + & + & + & + & + & Bacillus cereus & KY_750690 & 96.50 & + & & & & & + & nd \\
\hline Phenyl5 & + & + & + & + & + & + & Bacillus cereus & KY_930702 & 98.60 & + & & & & & - & nd \\
\hline Phenyl6 & + & + & + & + & + & + & Achromobacter sp. & CP_034689 & 98.09 & + & & & & & + & nd \\
\hline Pir1 & + & + & + & + & + & + & $\begin{array}{l}\text { Lysinbacillus } \\
\text { cresolivorans }\end{array}$ & NR_145635 & 100.0 & & + & & & & + & nd \\
\hline Tween80.1 & + & + & + & + & + & + & Lysinbacillus sp. & MN_365107 & 96.40 & & & + & & & + & + \\
\hline Tween80.2 & + & + & + & + & + & + & $\begin{array}{l}\text { Lysinbacillus } \\
\text { fusiformis }\end{array}$ & NR_112569 & 99.00 & & & + & & + & & nd \\
\hline Ita1 & + & + & + & + & + & + & Bacillus cereus & KC_849453 & 98.40 & & & & + & & + & + \\
\hline Ita2 & + & + & + & + & + & + & Microbacterium sp. & JF_505991 & 99.00 & & & & + & & nd & nd \\
\hline
\end{tabular}




\subsection{Isolation of Gram-Positive Species}

Gram-positive bacteria were isolated utilising humic acids as carbon sources. A total of 11 OTUs were retrieved after the screening the different morphotypes by ARDRA analysis. Four OTUs were shown to be capable of utilising each carbon source as the sole one, as well as their mixture (Table 2). The corresponding $16 \mathrm{~S}$ rDNAs were sequenced for taxonomic identification.

\subsection{Isolation of Generalist Species}

For the isolation of the generalist bacterial strains, Eco-plates ${ }^{\mathrm{TM}}$ were used as a tool to retrieve bacterial species able to grow on different carbon sources, mimicking soil environmental conditions, where multiple carbon sources are present. Bacterial strains able to metabolise each of the 31 different carbon sources present in the Eco-plates ${ }^{\mathrm{TM}}$, developed a purple colour, spectrophotometrically measured during the incubation time. After 3 days of incubation, eight different carbon sources, pyruvic acid methyl ester, Tween 40, Tween 80 , glycogen, itaconic acid, asparagine, phenylethyl amine, and putrescine showed a purple colour. After 6 days of incubation, six additional carbon sources, D-xylose, i-erythritol, $\mathrm{N}$-acetyl-glucosamine, phenylalanine, D-galacturonic acid, and $\gamma$-lactone, showed bacterial growth. After 7 days of incubation, four additional carbon sources, arginine, $\alpha$-cyclodextrin, D-mannitol, and hydroxybenzoic acid, showed bacterial growth. The isolates retrieved after the measurement of growth in the Eco-plate ${ }^{\mathrm{TM}}$ wells were analysed by ARDRA analysis and each OTU was tested for its capacity to grow on the different recalcitrant carbon sources and their mixture, as sole carbon sources. A total of 11 OTUs were retrieved and the corresponding $16 \mathrm{~S}$ rDNAs were sequenced for taxonomic identification (Table 2). Among the 11 OTUs only the Tween80.2 isolate, identified as Lysinbacillus fusiformis, was able to utilise both Tween-80 and glycogen for growth. All the other OTUs utilised a single carbon source, being the one contained in the Eco-plates ${ }^{\mathrm{TM}}$.

\subsection{Testing for the Plant Growth Promoting Activity}

OTUs, capable of utilising different recalcitrant carbon sources and their mixture as sole carbon sources, were tested for 1-aminocyclopropane-1-carboxylic acid deaminase activity and for their capacity to produce indole-3-acetic acid (IAA). Results obtained are reported in Table 2, with the taxonomic identification and metabolic potential of all the isolated strains.

\subsection{Taxonomic Analysis}

Results related to the taxonomic profiles of the bacterial community characterising the historically contaminated soil are reported in Figure 1. The analyses were reported for each soil sample analysed, with biological replicates considered, to verify the homogeneity of the microbial community across the analysed site area. The results obtained showed very similar profiles. The $16 \mathrm{~S}$ rRNA metabarcoding comprised all the genera of the isolated strains. Unclassified Gammaproteobacteria represented the most abundant class recovered in the soil. Of the Gammaproteobacteria, 13.2\% were unclassified at a lower taxa level. Gammaproteobacteria was comprised of the two isolated Pseudomonas sps. strains (Table 2). The unclassified Alcaligenaceae, representing a 3.13\% abundance relative to the total, was comprised of the isolated Achromobacter sp. strain (Table 2). Unclassified Bacillales representing $0.92 \%$ in relative abundance, was comprised of the isolated Lysinibacillus sps., Microbacterium, Bacillus and Arthrobacter sps., representing respectively the 3.38\%, 1.03\% and $0.95 \%$ abundance relative to the total, comprising the corresponding isolated strains (Table 2). 


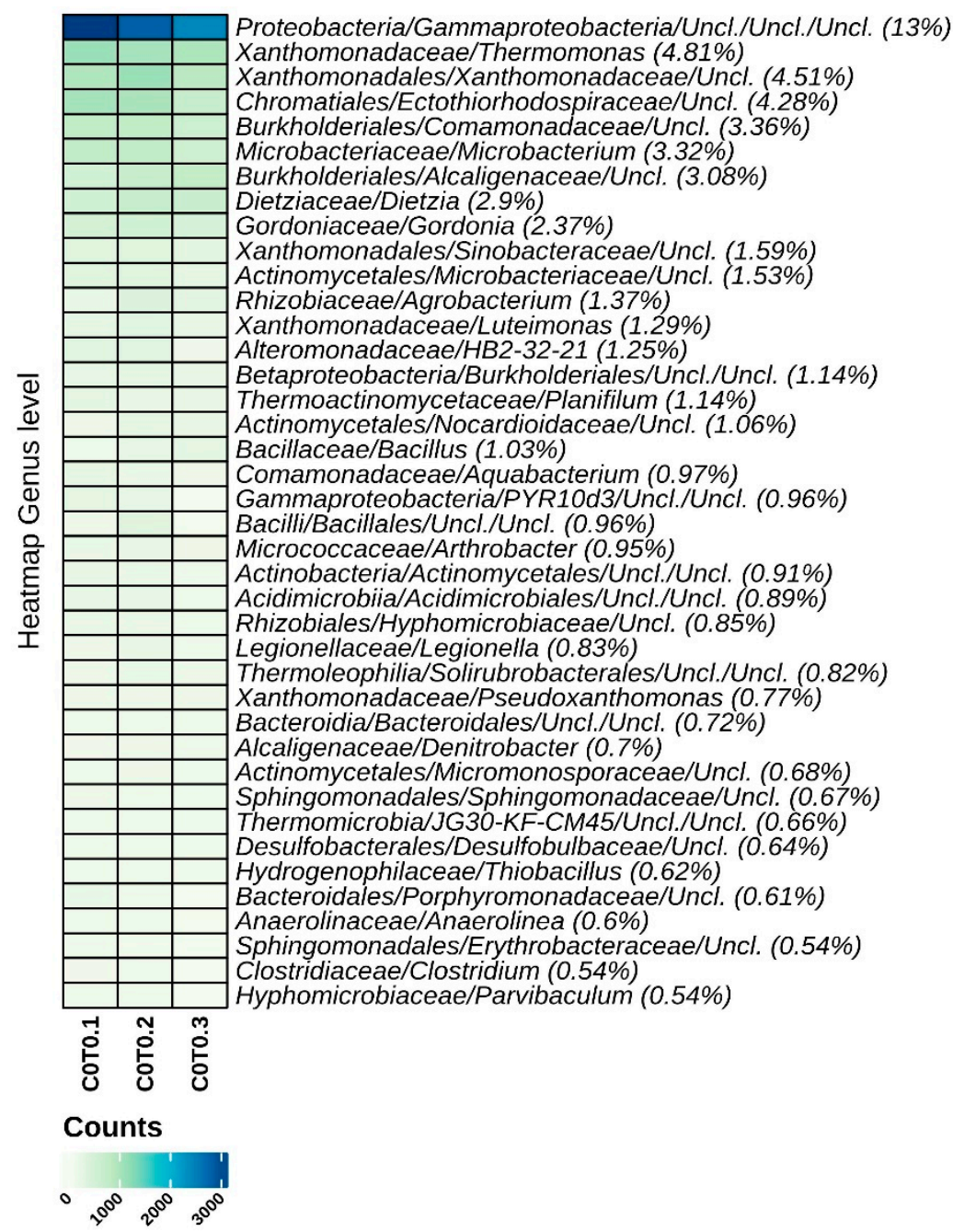

Figure 1. Taxonomic Heatmap showing the 40 most abundant ASVs in terms of absolute counts, aggregated at the Genus level for three biological replicates of the contaminated soil. On each row the nearest identified taxonomic levels, per ASV, are reported. The following percentage indicates their abundance relative to the total. Hierarchical clustering was performed on columns by Pearson correlation, based on Euclidean distance.

\subsection{Predictive Functional Metagenomic Analysis}

To better evaluate the metabolic potential of the different bacterial taxa colonising the contaminated soil, the contribution of the different bacterial taxa to the abundance of functional features of interest, such as the ones involved in xenobiotic degradation and PGP activity, were evaluated. To achieve this, a predictive functional metagenomic approach was adopted. Results were inferred to recover the taxa principally involved in the features of interest, with a particular interest in the potential contribution of the isolated strains. In relation to the functional features that are associated with the capacity of a bacterial community to transform contamination, the Dye decolourising peroxidase (DyP) was evaluated due to its capacity to oxidise phenolic compounds extracellularly and, as already described, it is involved in TPH depletion $[8,20]$. Results obtained are reported in Figure 2. DyP activity was predominantly associated with Dietziaceae, contributing to $47 \%$ of the function, followed by Gordoniaceae with 19\%. Both families were represented by one genus, Dietzia and Gordonia sps., respectively. Arthrobacter sp., that may comprise the isolated strains, contributed to $7.73 \%$. Unclassified Microbacteriaceae, representing $0.03 \%$ might comprise the Microbacterium sp. isolated strain. The latter might also comprise the unclassified Actinomycetales, accounting for $4.42 \%$ of the total. 


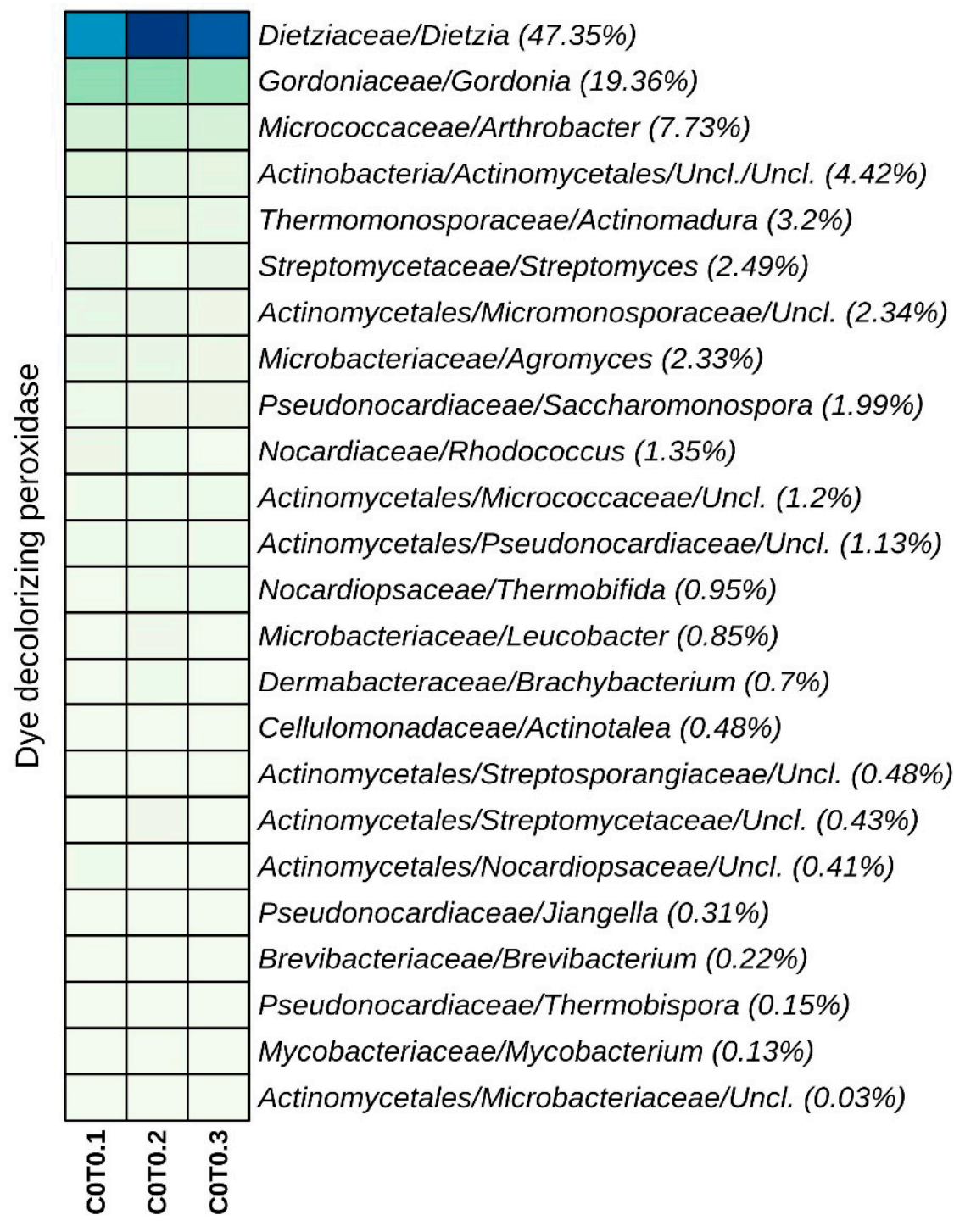

Counts

- $8^{\circ} 7^{0^{\circ}} 2^{60^{\circ}}$

Figure 2. Functional Heatmaps of the Dye decolourising peroxidase enzyme contribution by identified ASVs aggregated at the Genus level, as inferred by PICRUSt2 in the three biological replicates. On rows, the nearest identified taxonomic level for each contributing ASV is reported, followed by its relative percentage contribution to the functional feature. Hierarchical clustering of columns was performed by Pearson correlation, based on Euclidean distance.

In relation to the Alkane 1-monoxygenases involved in the initial oxidation of alkanes, which compose the saturated fraction of TPH [21], the results are reported in Figure 3. The biodiversity of the bacterial taxa contributing to this feature was lower than that recorded for DyP, as was the number of counts per taxa contribution. Dietzia sp. showed the highest contribution with $42.5 \%$ of the total. None of the isolated bacterial taxa were represented among the taxa contributing to the Alkane 1-monoxygenase activity. 


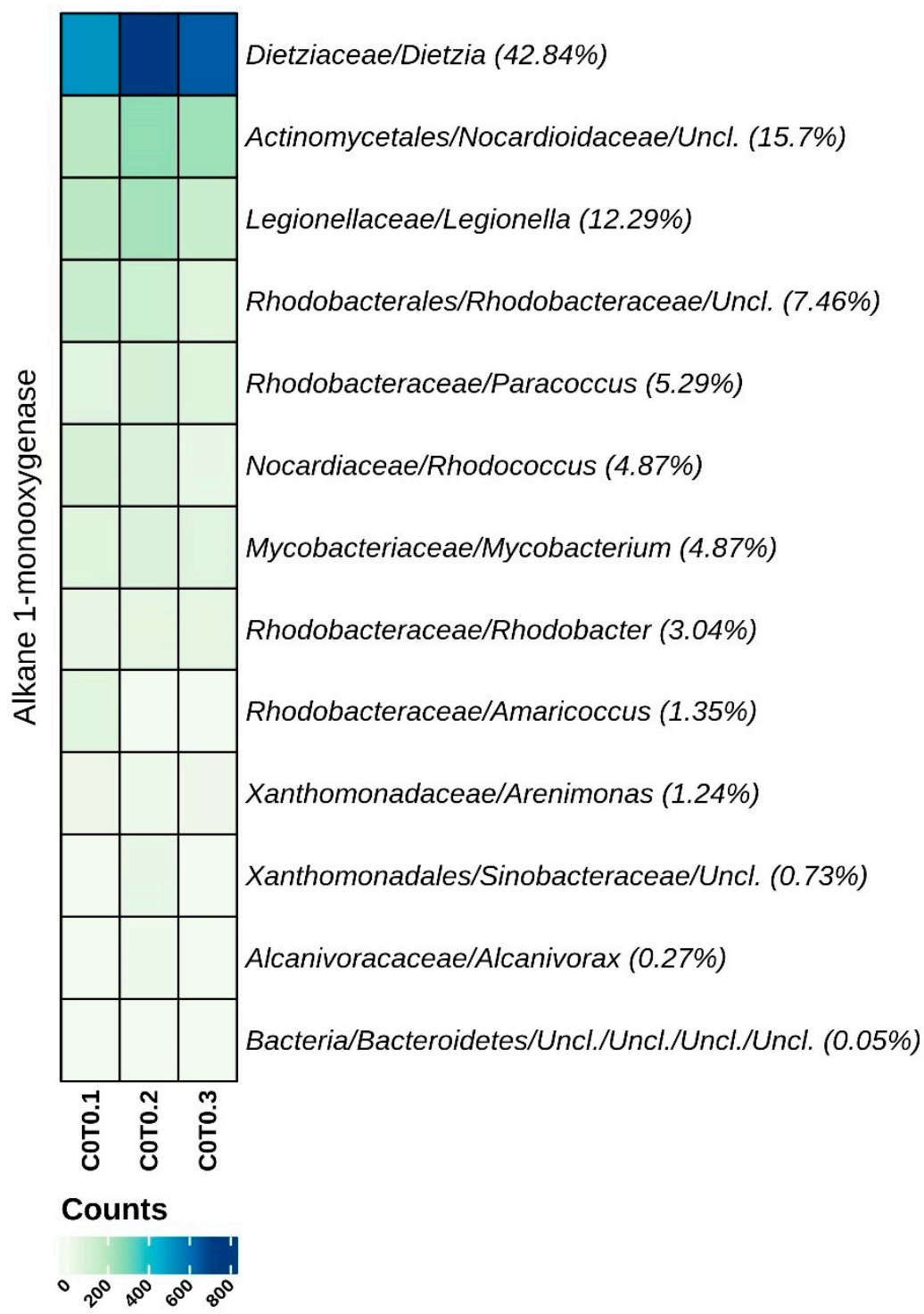

Figure 3. Functional Heatmaps of the Alkane 1-monooxygenase contribution by identified ASVs aggregated at the Genus level, as inferred by PICRUSt2 in the three biological replicates. On rows, the nearest identified taxonomic level for each contributing ASV is reported, followed by its relative percentage contribution to the functional feature. Hierarchical clustering of columns was performed by Pearson correlation, based on Euclidean distance.

Results obtained in relation to the Cathechol 1,2-dioxygenases are reported in Figure 4. Cathechol 1,2-dioxygenases are involved in the lower pathway of aromatic compound degradation via 3-oxoadipate [22], specifically in the ortho-cleavage of the cathecol aromatic ring. The biodiversity of the contributing bacterial taxa and the number of counts per taxa recorded were similar to those recorded for DyP. Dietzia and Gordonia sps. were predominant in their contribution with $17.4 \%$ and the $28.4 \%$, respectively. Thermomonas sp. contributed to $28.5 \%$ of the total. The contribution of the isolated genera Arthrobacter and Pseudomonas sps. represented 5.67\% and 1.94\%, respectively. The unclassified Burkholderiaceae, accounting for $0.19 \%$, might comprise the Achromobacter sp. isolated strain. 




Figure 4. Functional Heatmaps of the Cathechol 1,2-dioxygenase contribution by identified ASVs aggregated at the Genus level, as inferred by PICRUSt2 in the three biological replicates. On rows, the nearest identified taxonomic level for each contributing ASV is reported, followed by its relative percentage contribution to the functional feature. Hierarchical clustering of columns was performed by Pearson correlation, based on Euclidean distance.

A further dioxygenase involved in the lower pathway of aromatic compound degradation via 3-oxoadipate, and in the super-pathway of aromatic compound degradation via 2-hydroxypentadienoate [23], is Cathecol 2,3-dioxigenase. The number of contributing taxa to this feature and the number of counts for taxa were similar to those for Cathechol 1,2-dioxygenase (Figure 5). The highest contribution was due to Microbacterium sp. (20.65\%), comprising the isolated genera Dietzia and Gordonia sps., which contributed respectively to $8.17 \%$ and $6.68 \%$ of the total. The isolated genus Arthrobacter sp. contributed $5.33 \%$, Bacillus sp. $2.59 \%$ and unclassified Bacillales, that might comprise the Lysinibacillus sps. isolated strains, contributed $2.23 \%$. Unclassified Psueudomonadaceae, accounting for $1.31 \%$, might comprise the Pseudomonas sps. isolated strains in addition to the reported $0.91 \%$ contribution of the genus. 


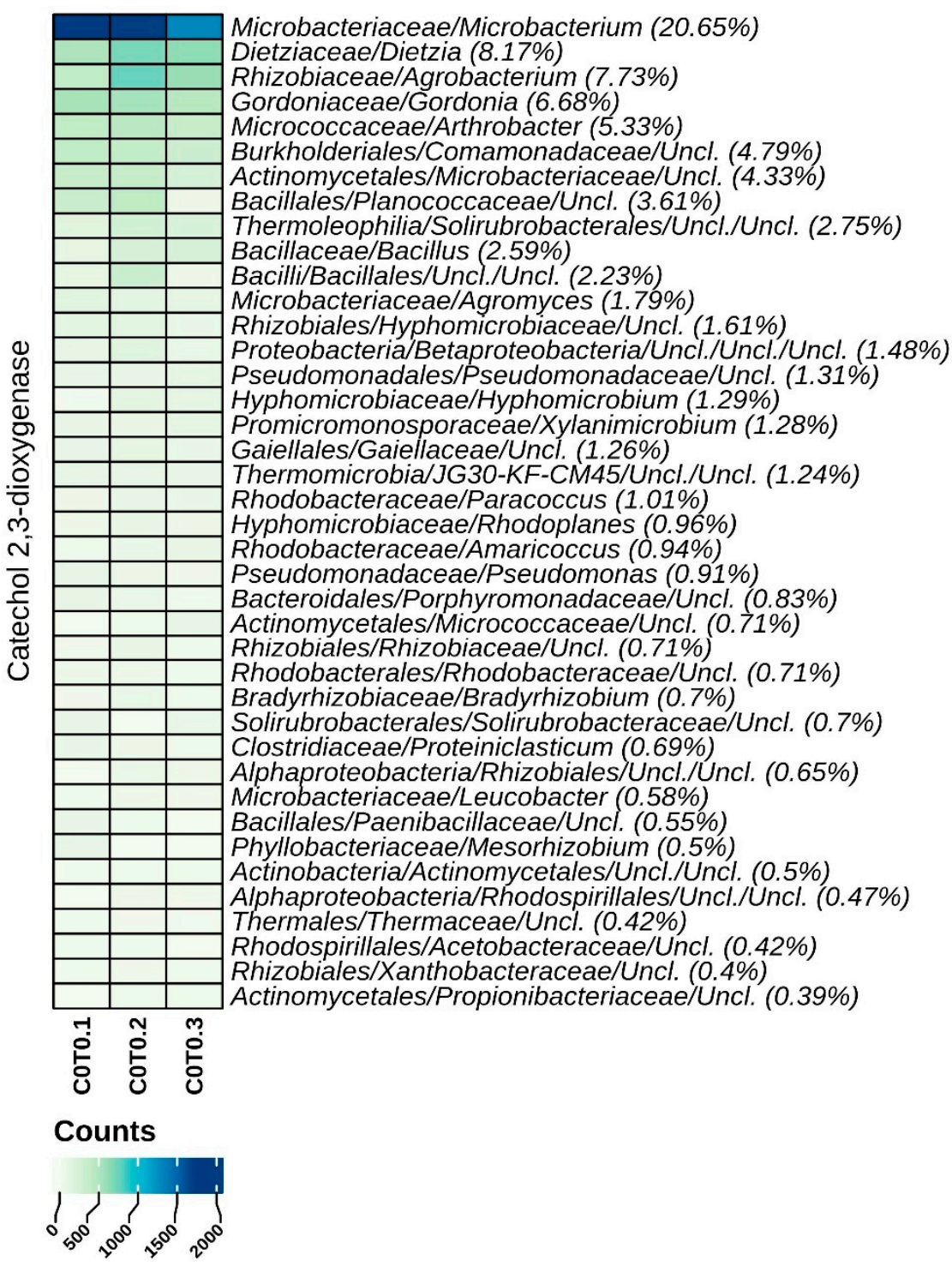

Figure 5. Functional Heatmaps of the Cathechol 2,3-dioxygenase contribution by identified ASVs aggregated at the Genus level, as inferred by PICRUSt 2 in the three biological replicates. On rows, the nearest identified taxonomic level for each contributing ASV is reported, followed by its relative percentage contribution to the functional feature. Hierarchical clustering of columns was performed by Pearson correlation, based on Euclidean distance.

Protocatechuate 3,4-dioxygenase is involved in the lower pathway of a second branch of the super-pathway of aromatic compound degradation via 3-oxoadipate [24], and it is involved in gentisate cleavage via the cleavage of protocatechuate. The biodiversity of the contributing taxa was similar to that already observed for the previously described dioxygenases, however the number of counts per taxa was lower. (Figure 6). The highest contribution was due to Agrobacterium sp. (13.8\%), followed by Arthrobacter sp. (9.52\%) and Microbacterium sp. (8.85\%). Pseudomonadaceae, that might comprise the Pseudomonas sp. isolated strains, contributed to $4.19 \%$ on the total. No significant contribution was recorded for the Bacillaceae or Alcaligenaceae families. However, the contribution of unclassified Burkholderiales, that might comprise the Achromobacter sp. isolate species, was recorded as $1.15 \%$. 


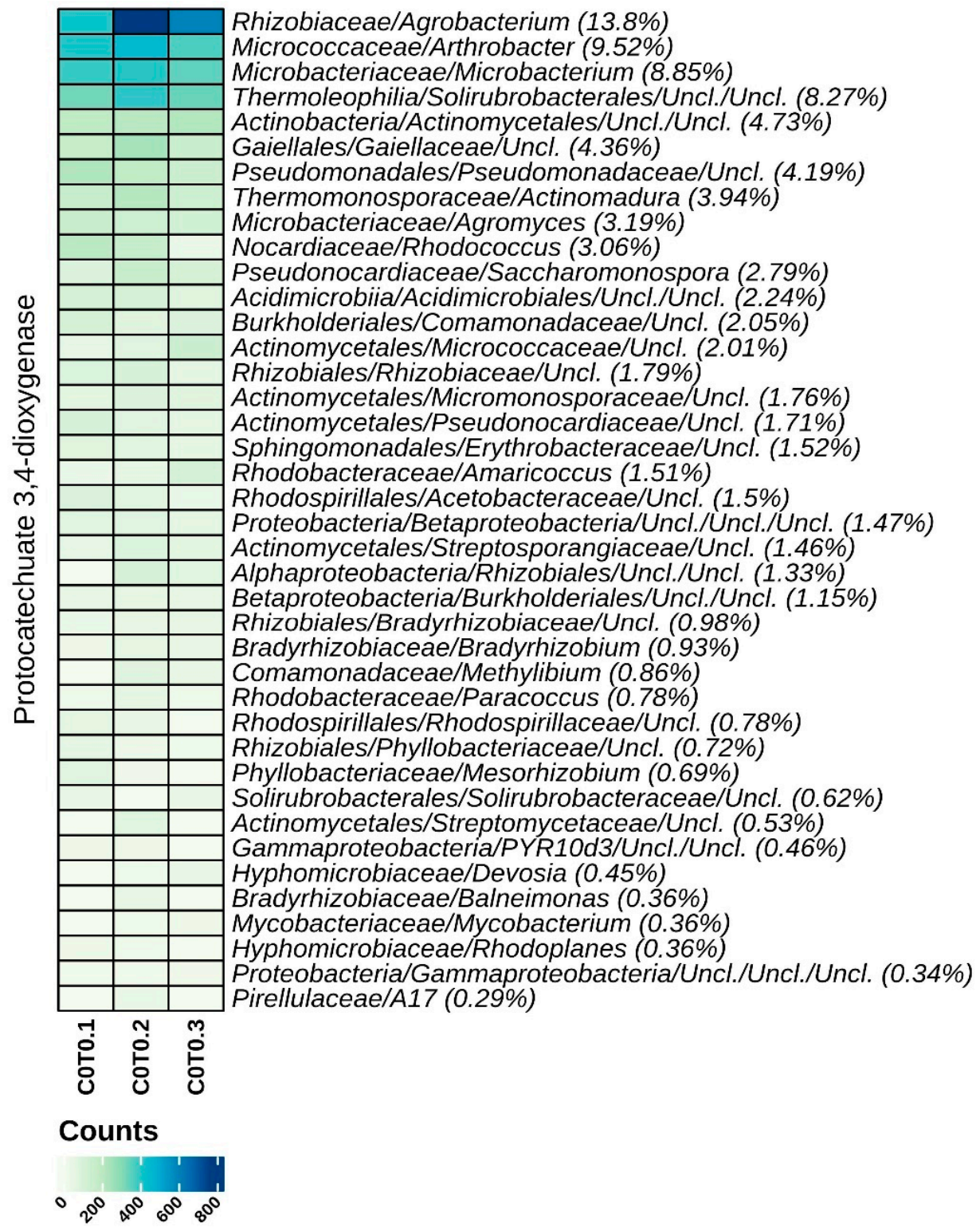

Figure 6. Functional Heatmaps of the Protocatechuate 3,4-dioxygenase contribution by identified ASVs aggregated at the Genus level, as inferred by PICRUSt2 in the three biological replicates. On rows, the nearest identified taxonomic level for each contributing ASV is reported, followed by its relative percentage contribution to the functional feature. Hierarchical clustering of columns was performed by Pearson correlation, based on Euclidean distance.

Gentisate 1,2 dioxigenase is involved in the aromatic ring cleavage of gentisate in mcresol oxidation [25]. The biodiversity of the contributing taxa was significantly lower than that recorded for the other dioxygenases, as was the number of counts per taxa (Figure 7). The highest contribution was due to Gordonia sp. (41.97\%). Achromobacter sp. contributed to $2.96 \%$ of the total, followed by an unclassified Pseudomonadaceae with $2.74 \%$, that might comprise the Pseudomonas sp. isolated strains. Unclassified Micrococcaceae, accounting for $0.93 \%$, might comprise the Arthrobacter sps. isolated strains. 


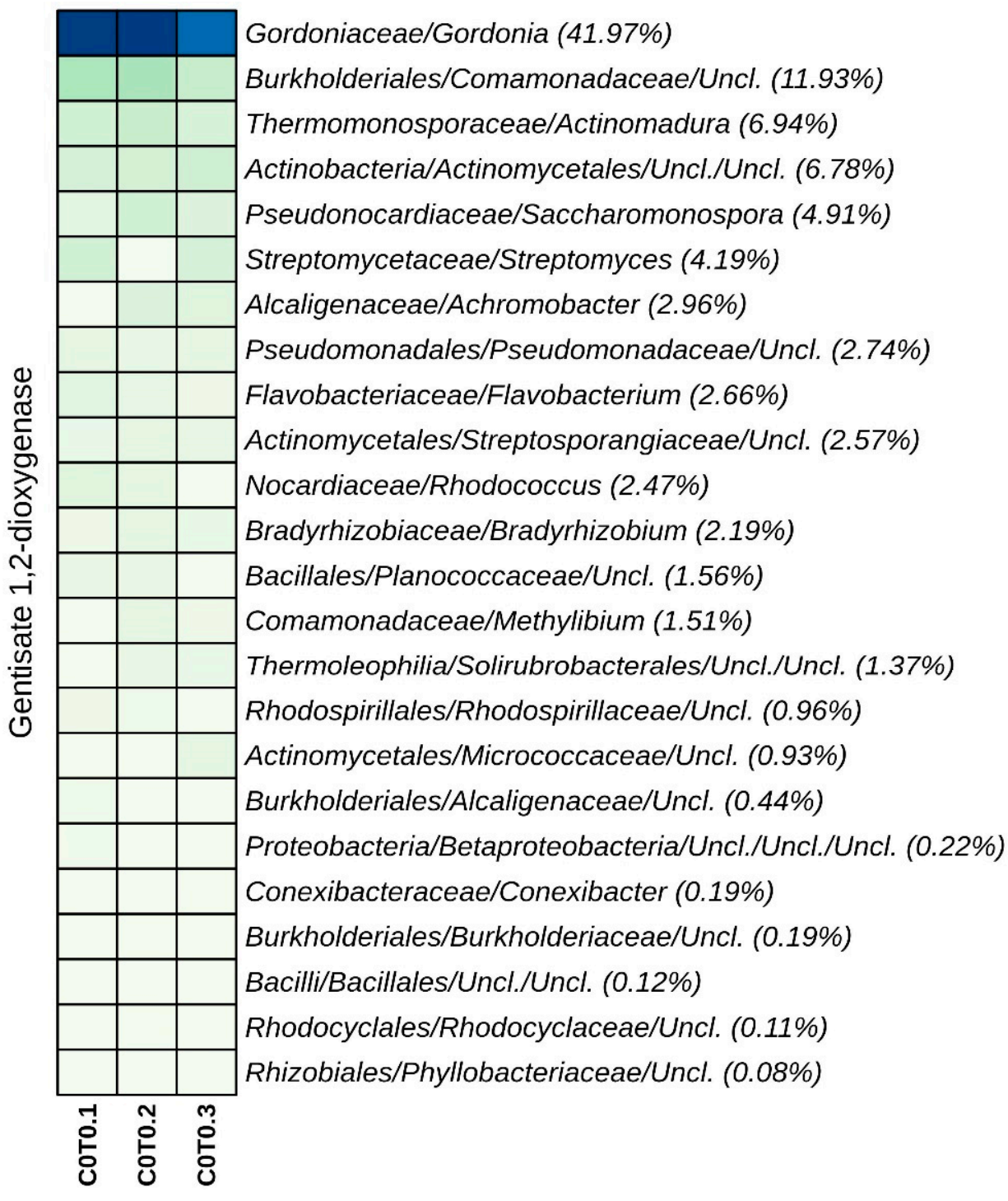

\section{Counts}



Figure 7. Functional Heatmaps of the Gentisate 1,2-dioxygenase contribution by identified ASVs aggregated at the Genus level, as inferred by PICRUSt2 in the three biological replicates. On rows, the nearest identified taxonomic level for each contributing ASV is reported, followed by its relative percentage contribution to the functional feature. Hierarchical clustering of columns was performed by Pearson correlation, based on Euclidean distance.

Benzoate 1,2-dioxigenase is responsible for the ring cleavage of benzoate, derived from the oxidative degradation of aromatic compounds like toluene [26] and 2-hydroxybiphenyl [27]. The total number of counts per taxa was the highest recorded with reference to the other dioxygenases, but the biodiversity of the contributing taxa was slightly lower (Figure 8). The highest contribution was due to Thermomonas sp. (26.99\%), followed by Gordonia (26.82\%) and Dietzia $(16.4 \%)$ sps. Arthrobacter sp. contributed to 5.35\% of the total and the Pseudomonas sp. contributed $1.83 \%$. Achromobacter sp. contributed $0.24 \%$. 


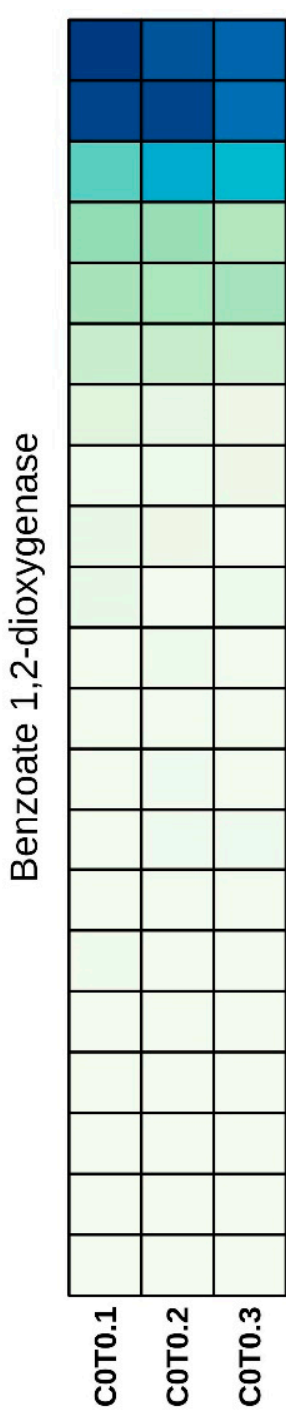

Xanthomonadaceae/Thermomonas (26.99\%)

Gordoniaceae/Gordonia (26.82\%)

Dietziaceae/Dietzia (16.4\%)

Burkholderiales/Comamonadaceae/Uncl. (9.62\%)

Xanthomonadaceae/Pseudoxanthomonas (8.83\%)

Micrococcaceae/Arthrobacter (5.35\%)

Pseudomonadaceae/Pseudomonas (1.83\%)

Pseudomonadales/Pseudomonadaceae/Uncl. (0.88\%)

Nocardiaceae/Rhodococcus (0.79\%)

Sphingomonadaceae/Novosphingobium (0.6\%)

Bradyrhizobiaceae/Bradyrhizobium (0.35\%)

Betaproteobacteria/Burkholderiales/Uncl./Uncl. (0.32\%)

Rhizobiales/Xanthobacteraceae/Uncl. (0.31\%)

Actinomycetales/Propionibacteriaceae/Uncl. (0.26\%)

Alcaligenaceae/Achromobacter (0.24\%)

Rhodobacteraceae/Amaricoccus (0.15\%)

Mycobacteriaceae/Mycobacterium (0.09\%)

Proteobacteria/Betaproteobacteria/Uncl./Uncl./Uncl. (0.07\%)

Burkholderiales/Burkholderiaceae/Uncl. (0.06\%)

Burkholderiales/Alcaligenaceae/Uncl. (0.04\%)

Rhodocyclales/Rhodocyclaceae/Uncl. (0.02\%)

Counts

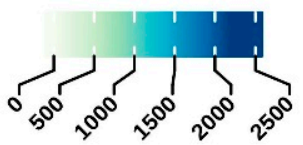

Figure 8. Functional Heatmaps of the Benzoate 1,2-dioxygenase contribution by identified ASVs aggregated at the Genus level, as inferred by PICRUSt2 in the three biological replicates. On rows, the nearest identified taxonomic level for each contributing ASV is reported, followed by its relative percentage contribution to the functional feature. Hierarchical clustering of columns was performed by Pearson correlation, based on Euclidean distance.

The contribution of the bacterial community to plant growth promotion capacity was also evaluated. In Figure 9 the contribution of bacterial taxa to the 1-aminocyclopropane1-carboxylate deaminase activity is reported. This enzyme is involved in inhibiting the production of ethylene, the plant hormone signalling a plant stress response to the environment [27]. The most relevant contributors to aminocyclopropane-1-carboxylate deaminase activity were the Microbacterium sp. (25.97\%). Pseudomonas (4.06\%) and Achromobacter sps., which contributed respectively to $5.22 \%, 4.06 \%$ and $1.05 \%$ of the total. Unclassified Micrococcaceae, that might comprise the Arthobacter sps. isolated strains, contributed to $0.66 \%$ of the total. 


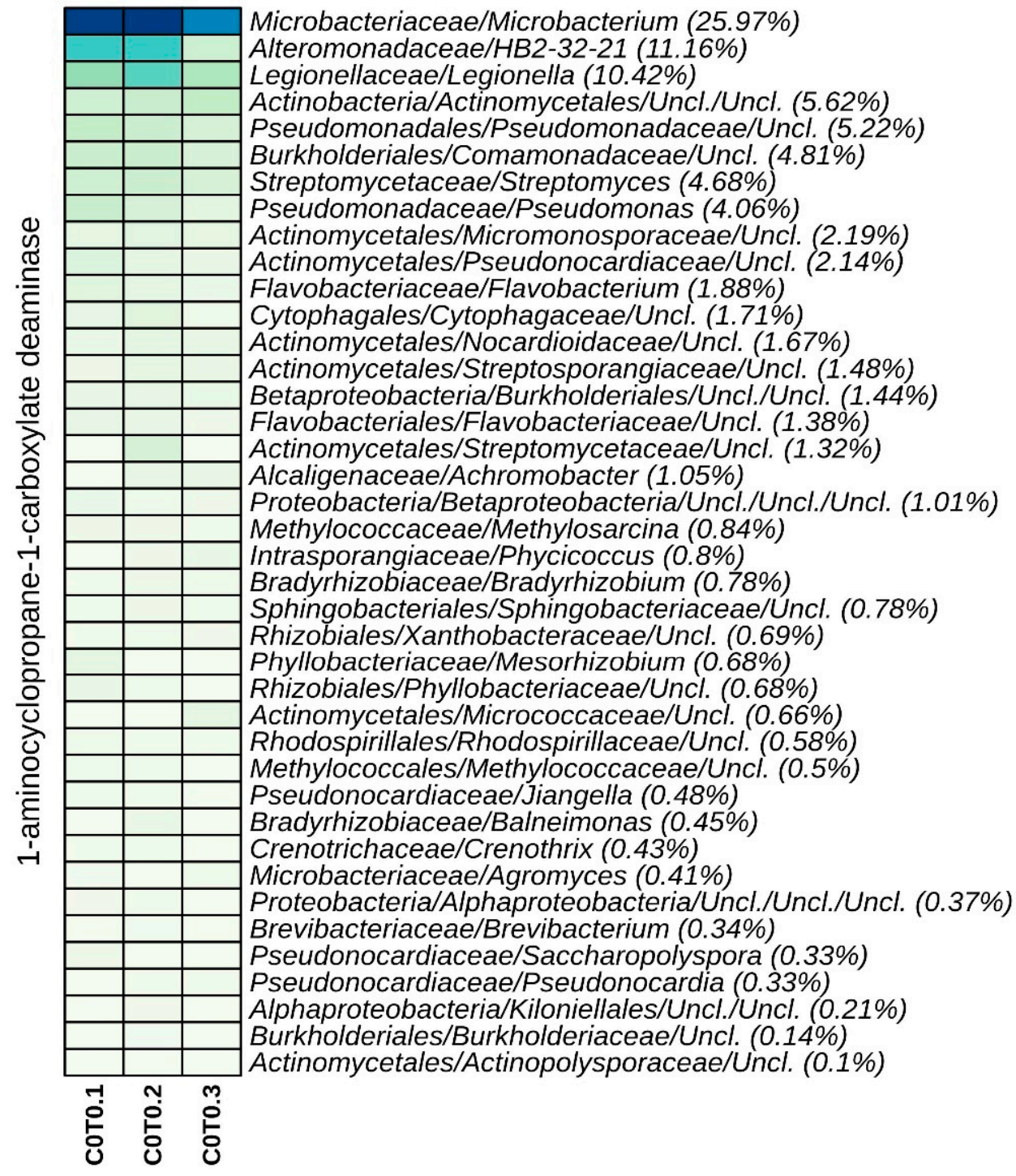

Microbacteriaceae/Microbacterium (25.97\%)

(1)

Actinobacteria/Actinomycetales/Uncl./Uncl. (5.62\%)

Pseudomonadales/Pseudomonadaceae/Uncl. (5.22\%)

Pseudomonadaceae/Pseudomonas (4.06\%)

Actinomycetales/Micromonosporaceae/Uncl. (2.19\%)

Flavobacteriaceae/Flavobacterium (1.88\%)

Cytophagales/Cytophagaceae/Uncl. (1.71\%)

Actinomycetales/Streptosporangiaceae/Uncl. (1.48\%)

Betaproteobacteria/Burkholderiales/Uncl./Uncl. (1.44\%)

Flavobacteriales/Flavobacteriaceae/Uncl. (1.38\%)

(1.01\%)

Bradyrhizobiaceae/Bradyrhizobium (0.78\%)

Sphingobacteriales/Sphingobacteriaceae/Uncl. (0.78\%)

Rhizobiales/Phyllobacteriaceae/Uncl. $(0.68 \%)$

Microbacteriaceae/Agromyces (0.41\%)

Brevibacteriaceae/Brevibacterium (0.34\%)

Pseudonocardiaceae/Saccharopolyspora $(0.33 \%)$

Pseudonocardiaceae/Pseudonocardia $(0.33 \%)$

Burkholderiales/Burkholderiaceae/Uncl. (0.14\%)

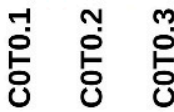

Counts

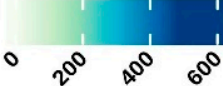

Figure 9. Functional Heatmaps of the Aminocyclopropane-1-carboxylate deaminase activity identified ASVs aggregated at the Genus level, as inferred by PICRUSt2 in the three biological replicates. On rows, the nearest identified taxonomic level for each contributing ASV is reported, followed by its relative percentage contribution to the functional feature. Hierarchical clustering of columns was performed by Pearson correlation, based on Euclidean distance.

Indole-3-pyruvate decarboxylase is involved in the bacterial production of the auxin indole-3-acetic acid (IAA) [28]. The biodiversity of the contributing taxa and the number of counts per taxa were lower than those contributing to the aminocyclopropane-1-carboxylate deaminase activity (Figure 10). The most relevant contributors were Legionella sp. (62.67\%), followed by Bradyrhizobium, sp. (4.67\%) and Bacillus sp., that contributed to $2.98 \%$ of the total. 


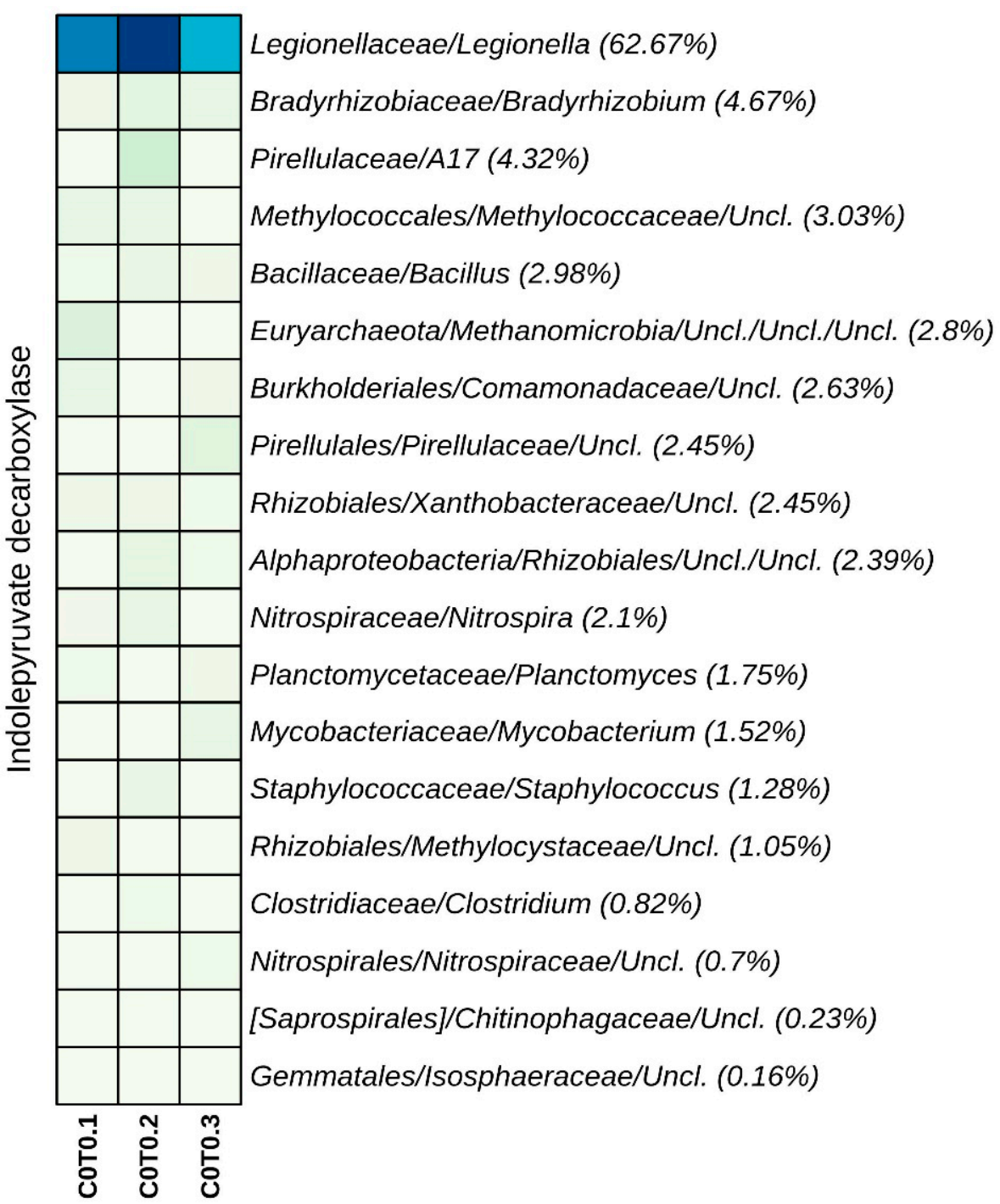

Counts

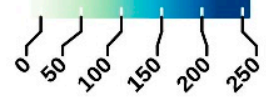

Figure 10. Functional Heatmaps of the indole-3-pyruvate decarboxylase identified ASVs aggregated at the Genus level, as inferred by PICRUSt2 in the three biological replicates. On rows, the nearest identified taxonomic level for each contributing ASV is reported, followed by its relative percentage contribution to the functional feature. Hierarchical clustering of columns was performed by Pearson correlation, based on Euclidean distance.

Tryptophan 2-monoxygenase is involved in the bacterial transformation of L-tryptophan to IAA [29]. The biodiversity of the contributing bacterial taxa and the number of counts per taxa were significantly low and distributed among unclassified taxa at the genus level (Figure 11). Streptomyces sp. contributed to $55.15 \%$ of the total and unclassified Streptomycetaceae to $7.55 \%$. The contribution of unclassified Micrococcaceae, that might comprise the Arthrobacter sps. isolated strains, was $29.52 \%$ of the total. 


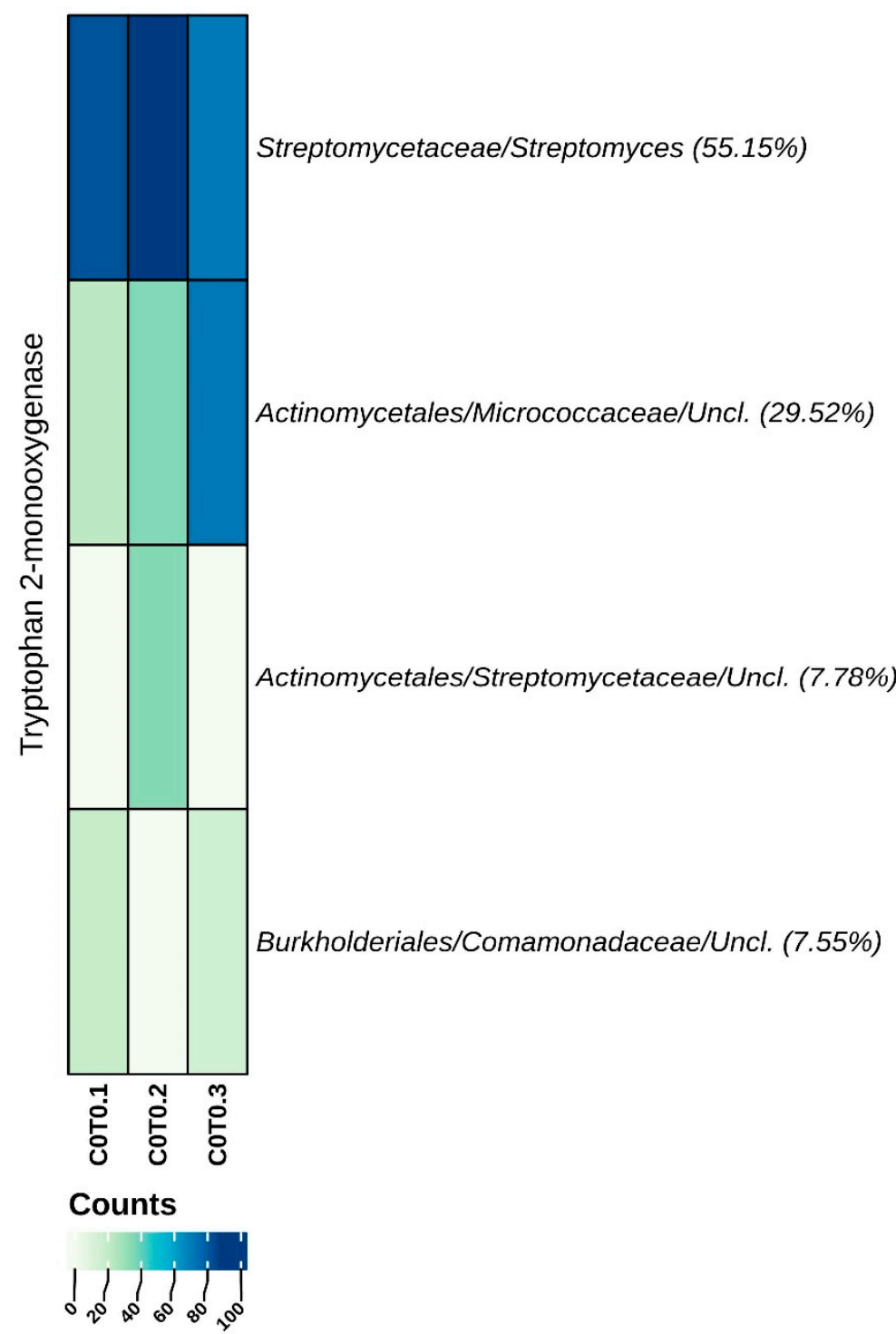

Figure 11. Functional Heatmaps of the Tryptophan 2-monoxygenase identified ASVs aggregated at the Genus level, as inferred by PICRUSt2 in the three biological replicates. On rows, the nearest identified taxonomic level for each contributing ASV is reported, followed by their relative percentage of contribution to the functional feature. Hierarchical clustering of columns was performed by Pearson correlation, based on Euclidean distance.

\section{Discussion}

The industrial exploitation of bio-based technologies for the treatment of TPH contaminated soils is infrequent, since it is time consuming and there is uncertainty in successful results. On the other hand, these approaches are extensively described in the literature as successful in the laboratory and at the pilot scale [30-34]. These experiments are, most of the time, associated with high levels of control of the different experimental parameters, to optimise the metabolism of the microorganisms competent in depleting the contamination. Molecular tools have been developed for monitoring the performance of microbial catalysts on biodegradation processes. These tools are, most of the time, proxies for the success of the bio-based process, and they can be considered as game changers in the selection of bio-based decontamination technologies, and should be applied at a real and industrial scale.

The advent of metagenomics is providing an acceleration in the knowledge, and eventually the regulation, of complex microbial processes in environmental matrices. The improvement of bio-based technologies might be dependent on the application of metage- 
nomic approaches. Bacterial metabarcoding and predictive functional metagenomic analysis have been successfully applied to study the involvement of different bacterial groups in biodegradation processes in the environment $[7,8]$. On the other hand, metagenomic approaches cannot be exhaustive in identifying the unknown content of microbial communities. Culturomic approaches provide valuable instruments for the isolation, discovery, and rigorous description of new microbial taxa, expanding our knowledge on soil biodiversity. In fact, microbial catalysts should be isolated and characterised with reference to their metabolic capacities. Moreover, these characterised taxa should be exploited for designing bioaugmentation approaches, since most of the time, bioaugmentation of microbial catalysts is associated with the acceleration of the process of biodegradation, with significant positive effects on the transferability of the bio-based technology to the industrial scale [35]. The combination of culture-independent and culture-dependent approaches is a powerful instrument for expanding our knowledge on the still black box of soil microbial communities which degrade persistent contaminants. At the same time this combination might be important for expanding the possibility of repeatability and success of bio-based approaches to the decontamination of environmental matrices.

However, culturomic approaches are limited by the selection of culture conditions to depict the complexity of the biodiversity of soil communities. In this experiment a new approach to the isolation of bacteria, competent for the biodegradation of the contamination, was adopted. In addition to the enrichment and isolation in axenic culture of specialist species which were capable of utilising the contamination as a sole carbon source, we adopted culture conditions that mimicked soil growth environments and favoured the blooming of diverse classes of soil bacterial communities. More precisely, Eco-plates ${ }^{\mathrm{TM}}$ were adopted, focussing on the under-investigated potential of generalist species in the processes of transforming recalcitrant compounds in biodegradation [8]. Exploited to delineate physiological traits of microbial communities, the Eco-plates ${ }^{\mathrm{TM}}$ provide a plethora of carbon sources, mimicking the soil, by actually providing a plethora of exudates and diverse carbonaceous complexes as carbon sources. Saprophytic generalist species bloom in the presence of diverse and multiple carbon sources, present at low concentrations in soil [2]. It has been observed that the blooming of these saprophytic microorganisms is responsible for an increase in the bioavailability of contamination and an increase in the metabolic activity of hydrocarbonoclastic species [8]. The isolation of autochthonous generalist species adapted to contamination is attractive, and their participation in the transformation of contamination, by its utilisation as a carbon source is desirable. Thus, in parallel to the selection by Eco-plates ${ }^{\mathrm{TM}}$, we assessed the capacity of the isolated generalist strains to metabolise recalcitrant compounds. The same rationale was adopted for the isolation of Gram-positive bacteria, utilising humic acids as the sole carbon source for growth. The interest in this class of microorganisms was due to the evidence that Gram-positive bacteria have been described as significantly efficient in the degradation of polyaromatic structures, recalcitrant to biodegradation [11]. On the other hand, specialist species, enriched because they are capable of efficiently transforming contamination for growth, were isolated by the adoption of a conserved approach, dedicated to the isolation of microorganisms that use recalcitrant compounds as a sole carbon source, when provided at significantly high concentrations.

The culturomic approach adopted for the enrichment of Gram-positive species ended up with the exclusive isolation of Bacillus sps., and the approach dedicated to the isolation of generalist species led to the isolation mainly of Bacillus sps. In both cases the strains were capable of utilising each recalcitrant substrate as a sole carbon source, as well as their mixture, showing a high versatility in metabolic potential of the taxa. Bacillus sp. was not dominant in the microbial community colonising the contaminated soil, however, at a functional level, the genus was associated with a significant contribution to the degradation of aromatic compounds, since they contributed to the lower pathway of the oxidation of polyaromatic compounds via 3-oxoadipate and 2-hydroxypentadienoate. Actually, Bacillus sp. has been described as capable of degrading both diesel oil and different 
complex and recalcitrant hydrocarbonoclastic mixtures, such as crude oil [36,37]. The metabolic versatility of the genus was confirmed by the evidence that most of the isolated Bacillus sp. strains were capable of producing IAA. On the other hand, Bacillus sp. did not contribute to an inhibition of the plant response to environmental stresses, via 1amminocyclopropane carboxylic acid decarboxylase activity. Bacillus sp. are interestingly described in the literature as promising candidates to produce IAA [38]. IAA is a signalling molecule essential for plant-microbe interactions, modulating the growth of the plant root apparatus with important effects on plant nutrition [39]. The observed capacity of Bacillus sps. isolates to produce IAA might reasonably derive from the evidence that the site of sampling of the contaminated soil was vegetated, despite being a hot spot of contamination and associated toxicity.

In the context of reclamation of a contaminated area, revegetation of the same area might be essential to accelerate the recovery of soil resilience. Vegetation of a contaminated soil is associated with eliciting metabolic activity in contaminant degrading bacterial communities [40], and to their contribution in the depletion of residual levels of contamination and noxious intermediates of degradation from the primary pollutants [41]. The synergisms between bacteria and plants are very promising in the exploitation of bio-based technologies for the recovery of contaminated soils. Beneficial interactions between plants and Bacillus sp. has already been described [42,43], as well as beneficial interactions between plants and Lysinibacillus sp. [44]. The culturomic approach adopted here, also led to the isolation of Lysinobacillus sps. In relation to this genus, the functional metagenomic analysis inferred a contribution to the lower pathway of aromatic compound degradation via 3-oxoadipate and 2-hydroxypentadienoate. However, none of the Lysinibacillus sps. isolates were capable of PGP activity. Lysinibacillus sp. has already been described as being involved in the degradation of crude oil $[45,46]$. Here, PGP capacity was also not detected [47]. A more detailed characterisation of the isolates, by the sequencing of their genomes, will provide new functional traits that the culture and experimental conditions adopted here might have masked.

As previously described for Bacillus sp., the Arthrobacter sps. isolates were shown to be of considerable interest. The genus was not dominant in the contaminated soil, however, it contributed to all the different functional traits of interest analysed. Arthrobacter sps. contributed to the lower pathway of aromatic compound degradation via 3-oxoadipate; to the cleavage of gentisate in the m-cresol oxidation pathway, and to benzoate, derived from the oxidative degradation of aromatic compounds like toluene and 2-hydroxybiphenyl. At the same time, the genus contributed to phenolic extracellular oxidative activity by the Dye decolourising peroxidase. The metabolic versatility of the genus was confirmed by its PGP capacity, since the isolates produced IAA and the genus contributed to aminocyclopropane1-carboxylate deaminase activity. Arthrobacter sp. has been extensively described as a PGP bacterium $[48,49]$. On the other hand, the genus was also described as being involved in crude oil degradation $[50,51]$.

The contribution to the phenolic extracellular oxidative activity by the Dye decolourising peroxidase was also ascribable to Microbacterium sp. The feature is associated with microbial saprophytic metabolism, and the bacterial capacity to produce extracellular peroxidases for the transformation of organic matter in soil, is used for mobilising sources of carbon and nutrients in general. The feature is also involved in the extracellular oxidation of recalcitrant compounds [20]. The isolation of bacterial candidates, capable of extracellular and intracellular oxidising activity, might be pivotal to both increase the bioavailability of the contamination, that in contaminated soil constitutes the dominant organic matter portion, and to accelerate contaminant biodegradation. In this context it should be mentioned that Microbacterium sp. also contributed to the lower pathway of polycyclic aromatic compounds via 3-oxoadipate and 2-hydroxypentadienoate, and to gentisate cleavage via protocatechuate. Moreover, the genus showed PGP capacity by contributing to the aminocyclopropane-1-carboxylate deaminase activity, and the isolated strain was shown to be capable of producing IAA. Microbacterium sp. has been described 
as capable of degrading crude oil $[50,52]$ and has also been isolated from contaminated environments and exploited for PGP activity $[53,54]$.

The culturomic approach adopted here also led to the isolation of strains of the dominating Gammaproteobacteria. More precisely two strains of Pseudomonas sps. and one strain of Achromobacter sp. The two Pseudomonas sps. showed a high level of plasticity, since both isolates were capable of producing IAA and inhibited the synthesis of the plant hormone ethylene. Moreover, the genus showed a wide plasticity in the lower pathway for polycyclic aromatic degradation, contributing to all the intracellular oxidising activities analysed here. A contribution to the cleavage of benzoate derived from the oxidative degradation of aromatic compounds like toluene and 2-hydroxybiphenyl was also ascribed to the Achromobacter sp. genus, which also showed a contribution to the aminocyclopropane1-carboxylate deaminase activity and the isolated strain showed the capacity to produce IAA. Pseudomanas sp. has been described both as a PGP bacterium [54,55], and capable of degrading crude oil [50,56]. The same was observed for Achromobacter sp., as a PGP [57,58], and for being involved in crude oil degradation [59,60].

The biodiversity of bacteria contributing to the lower pathway of the oxidation of aromatic and condensed structures was here, significantly higher than the biodoversity contributing to the oxidation of the saturated fraction of the contamination, associated with 1-Alkhanomonoxygenase activity. The results suggest a significant potential of the bacterial community towards the aromatic and most recalcitrant fraction of TPH contamination. The culturomic approach confirmed this assumption since none of the genera of the isolated strains showed a significant contribution to 1-Alkhanomonoxygenase activity.

Thus, the culturomic approaches were successful in isolating promising bacterial strains capable of transforming the recalcitrant portion of the contamination. On the other hand, the culturomic approach failed in the isolation of both the most abundant taxa, and the taxa showing the highest contribution to the functional features of interest, suggesting a necessary implementation of the approach for a wider interpretation of the bacterial biodiversity in soils. However, the multivariate approach adopted here was shown to be a successful example of the utility of combining culture-dependent and culture-independent approaches, to evaluate the representativeness, both in taxonomic and functional terms, of isolated strains, as potential candidates for the design of bio-based approaches to soil decontamination. We confirmed the assessment that culturomic approaches are limited by the selection of culture conditions to depict the complexity of the biodiversity of soil communities. The multivariate approach to the enrichment of microorganisms of interest led to the isolation of a significant number of strains, largely higher than the numbers obtained by a classical protocol for the enrichment of specialist species (17 vs. 3 ).

\section{Conclusions}

The culturomic approach adopted here led to the isolation of 17 bacterial strains showing promising plasticity in terms of biodegradative potentiality and PGP activity. Most of them combine extracellular and intracellular oxidative capacities that can be exploited for both increasing the bioavailabilty of the contamination and the kinetics of its biodegradation. The potentiality of the isolated strains was confirmed by the predictive functional metagenomic analysis, suggesting that the combination of culturomic and molecular approaches is efficient in selecting bacterial candidates for the design of bio-based technologies for the treatment of contaminated soils. The approach to the isolation and characterisation of a hydrocarburoclastic microbial microbiome described here, can be adopted for constructing artificial hydrocarbonoclastic microbiota for environmental restoration.

Author Contributions: I.C., S.B.: conceptualization, investigation, validation, data curation, writing original draft; G.B.: data curation, formal analysis, methodology, software; G.S.: investigation, validation, data curation and S.D.G.: conceptualization, validation, data curation, writing-reviewing and editing original draft, supervision, project administration. All authors have read and agreed to the published version of the manuscript. 
Funding: This work was funded by the Bioresnova project 135/11 and co-financed by Fondazione Pisa and the Department of Biology, University of Pisa.

Institutional Review Board Statement: Not applicable.

Informed Consent Statement: Not applicable.

Data Availability Statement: The sequences have been deposited at the Sequence Read Archive (SRA) database, National Center for Biotechnology Information (NCBI) with the projects ID number PRJNA688285.

Conflicts of Interest: The authors declare no conflict of interest.

\section{References}

1. Van Liedekerke, M.; Prokop, G.; Rabl-Berger, S.; Kibblewhite, M.; Louwagie, G. Progress in the Management of Contaminated Sites in Europe; EUR 26376, JRC85913; Publications Office of the European Union: Luxembourg, 2013. [CrossRef]

2. Kuenen, J.G. The role of specialists and generalists in microbial-population interactions. In Foundations of Biochemical Engineering: Kinetics and Thermodynamic in Biological Systems; American Chemical Society: Boulder, CO, USA, 1982; pp. $230-251$.

3. Bell, T.H.; Stefani, F.O.; Abram, K.; Champagne, J.; Yergeau, E.; Hijri, M.; St-Arnaud, M. A Diverse Soil Microbiome Degrades More Crude Oil than Specialized Bacterial Assemblages Obtained in Culture. Appl. Environ. Microbiol. 2016, 82, 5530-5541. [CrossRef]

4. Strickland, M.S.; Lauber, C.; Fierer, N.; Bradford, M.A. Testing the functional significance of microbial community composition. Ecology 2009, 90, 441-451. [CrossRef] [PubMed]

5. Hawkes, C.V.; Kivlin, S.N.; Rocca, J.D.; Huguet, V.; Thomsen, M.A.; Suttle, K.B. Fungal community responses to precipitation. Glob. Chang. Biol. 2011, 17, 1637-1645. [CrossRef]

6. Jiao, S.; Chen, W.; Wei, G. Resilience and Assemblage of Soil Microbiome in Response to Chemical Contamination Combined with Plant Growth. Appl. Environ. Microbiol. 2019, 85, e02523-18. [CrossRef] [PubMed]

7. Mukherjee, A.; Chettri, B.; Langpoklakpam, J.S.; Basak, P.; Prasad, A.; Mukherjee, A.K.; Bhattacharyya, M.; Singh, A.K.; Chattopadhyay, D. Bioinformatic Approaches Including Predictive Metagenomic Profiling Reveal Characteristics of Bacterial Response to Petroleum Hydrocarbon Contamination in Diverse Environments. Sci. Rep. 2017, 7, 1-22. [CrossRef]

8. Becarelli, S.; Chicca, I.; La China, S.; Siracusa, G.; Bardi, A.; Gullo, M.; Petroni, G.; Levin, D.B.; Di Gregorio, S. A New Ciboria sp. for Soil Mycoremediation and the Bacterial Contribution to the Depletion of Total Petroleum Hydrocarbons. Front. Microbiol. 2021, 12, 647373. [CrossRef]

9. Glick, B.R. Using soil bacteria to facilitate phytoremediation. Biotechnol. Adv. 2010, 28, 367-374. [CrossRef]

10. Di Gregorio, S.; Giorgetti, L.; Ruffini Castiglione, M.; Mariotti, L.; Lorenzi, R. Phytoremediation for improving the quality of effluents from a conventional 2 tannery wastewater treatment plants. Int. J. Environ. Sci. Technol. 2015, 12, 1387-1400. [CrossRef]

11. Lăzăroaie, M. Multiple responses of gram-positive and gram-negative bacteria to mixture of hydrocarbons. Braz. J. Microbiol. 2010, 41, 649-667. [CrossRef]

12. Ventura, G.T.; Kenig, F.; Reddy, C.M.; Frysinger, G.S.; Nelson, R.K.; Van Mooy, B.; Gaines, R.B. Analysis of unresolved complex mixtures of hydrocarbons extracted from Late Archean sediments by comprehensive two-dimensional gas chromatography (GC $\times$ GC). Org. Geochem. 2008, 39, 846-867. [CrossRef]

13. Siles, J.A.; Rachid, C.T.; Sampedro, I.; García-Romera, I.; Tiedje, J.M. Microbial diversity of a Mediterranean soil and its changes after biotransformed dry olive residue amendment. PLOS ONE 2014, 9, e103035. [CrossRef]

14. Siles, J.A.; Cajthaml, T.; Minerbi, S.; Margesin, R. Effect of altitude and season on microbial activity, abundance and community structure in Alpine forest soils. FEMS Microbiol. Ecol. 2016, 92, fiw008. [CrossRef] [PubMed]

15. Hayakawa, M. Studies on the Isolation and Distribution of Rare Actinomycetes in Soil. Actinomycetologica 2008, 22, 12-19. [CrossRef]

16. Khanna, M.; Solanki, R.; Lal, R. Selective isolation of rare actinomycetes producing novel antimicrobial compounds. Int. J. Adv. Biotechnol. Res. 2011, 2, 357-375.

17. Weisburg, W.G.; Barns, S.M.; Pelletier, D.A.; Lane, D.J. 16S ribosomal DNA amplification for phylogenetic study. J. Bacteriol. 1991, 173, 697-703. [CrossRef] [PubMed]

18. Penrose, D.M.; Glick, B.R. Methods for isolating and characterizing ACC deaminase-containing plant growth-promoting rhizobacteria. Physi. Plant. 2003, 118, 10-15. [CrossRef] [PubMed]

19. Bric, J.M.; Bostock, R.M.; Silverstone, S.E. Rapid in situ assay for indoleacetic Acid production by bacteria immobilized on a nitrocellulose membrane. Appl. Environ. Microbiol. 1991, 57, 535-538. [CrossRef] [PubMed]

20. van Bloois, E.; Torres Pazmiño, D.E.; Winter, R.T.; Fraaije, M.W. A robust and extracellular heme-containing peroxidase from Thermobifida fusca as prototype of a bacterial peroxidase superfamily. Appl Microbiol Biotechnol. 2010, 86, 1419-1430. [CrossRef]

21. Shen, F.T.; Young, L.S.; Hsieh, M.F.; Lin, S.Y.; Young, C.C. Molecular detection and phylogenetic analysis of the alkane 1monooxygenase gene from Gordonia spp. Syst. Appl. Microbiol. 2010, 33, 53-59. [CrossRef]

22. Pérez-Pantoja, D.; Donoso, R.; Agulló, L.; Córdova, M.; Seeger, M.; Pieper, D.H.; González, B. Genomic analysis of the potential for aromatic compounds biodegradation in Burkholderiales. Environ. Microbiol. 2012, 14, 1091-1117. [CrossRef] 
23. Li, W.; Shi, J.; Wang, X.; Han, Y.; Tong, W.; Ma, L.; Liu, B.; Cai, B. Complete nucleotide sequence and organization of the naphthalene catabolic plasmid pND6-1 from Pseudomonas sp. strain ND6. Gene 2004, 336, 231-240. [CrossRef]

24. Shen, X.; Liu, S. Key enzymes of the protocatechuate branch of the beta-ketoadipate pathway for aromatic degradation in Corynebacterium glutamicum. Sci. China C Life Sci. 2005, 48, 241-249. [CrossRef]

25. Hopper, D.J.; Taylor, D.G. Pathways for the degradation of m-cresol and p-cresol by Pseudomonas putida. J. Bacteriol. 1975, 122, 1-6. [CrossRef]

26. Haigler, B.E.; Spain, J.C. Biodegradation of 4-nitrotoluene by Pseudomonas sp. strain 4NT. Appl. Environ. Microbiol. 1993, 59, 2239-2243. [CrossRef] [PubMed]

27. Nascimento, F.X.; Rossi, M.J.; Glick, B.R. Ethylene and 1-Aminocyclopropane-1-carboxylate (ACC) in Plant-Bacterial Interactions. Front. Plant Sci. 2018, 9, 114. [CrossRef] [PubMed]

28. Phi, Q.T.; Park, Y.M.; Ryu, C.M.; Park, S.H.; Ghim, S.Y. Functional identification and expression of indole-3-pyruvate decarboxylase from Paenibacillus polymyxa E681. J. Microbiol. Biotechnol. 2008, 18, 1235-1244. [PubMed]

29. Kosuge, T.; Heskett, M.G.; Wilson, E.E. Microbial synthesis and degradation of indole-3-acetic acid. I. The conversion of Ltryptophan to indole-3-acetamide by an enzyme system from Pseudomonas savastanoi. J. Biol. Chem. 1966, 241, 3738-3744. [CrossRef]

30. Jørgensen, K.S.; Puustinen, J.; Suortti, A.M. Bioremediation of petroleum hydrocarbon-contaminated soil by composting in biopiles. Environ. Pollut. 2000, 107, 245-254. [CrossRef]

31. Gomez, F.; Sartaj, M. Field scale ex-situ bioremediation of petroleum contaminated soil under cold climate conditions. Int. Biodeterior. Biodegrad. 2013, 85, 375-382. [CrossRef]

32. Gomez, F.; Sartaj, M. Optimization of field scale biopiles for bioremediation of petroleum hydrocarbon contaminated soil at low temperature conditions by response surface methodology (RSM). Int. Biodeterior. Biodegrad. 2014, 89, 103-109. [CrossRef]

33. Martínez Álvarez, L.M.; Ruberto, L.; Lo Balbo, A.; Mac Cormack, W.P. Bioremediation of hydrocarbon-contaminated soils in cold regions: Development of a pre-optimized biostimulation biopile-scale field assay in Antarctica. Sci. Total Environ. 2017, 590, 194-203. [CrossRef]

34. Cai, P.; Ning, Z.; Liu, Y.; He, Z.; Shi, J.; Niu, M. Diagnosing bioremediation of crude oil-contaminated soil and related geochemical processes at the field scale through microbial community and functional genes. Ann. Microbiol. 2020, 70, 1-15. [CrossRef]

35. Benyahia, F.; Embaby, A.S. Bioremediation of Crude Oil Contaminated Desert Soil: Effect of Biostimulation, Bioaugmentation and Bioavailability in Biopile Treatment Systems. Int. J. Environ. Res. Public Health 2016, 13, 219. [CrossRef]

36. Raju, M.N.; Leo, R.; Herminia, S.S.; Morán, R.E.; Venkateswarlu, K.; Laura, S. Biodegradation of Diesel, Crude Oil and Spent Lubricating Oil by Soil Isolates of Bacillus spp. Bull. Environ. Contam Toxicol. 2017, 98, 698-705. [CrossRef]

37. Khanpour-Alikelayeh, E.; Partovinia, A.; Talebi, A.; Kermanian, H. Investigation of Bacillus licheniformis in the biodegradation of Iranian heavy crude oil: A two-stage sequential approach containing factor-screening and optimization. Ecotoxicol. Environ. Saf. 2020, 205, 111103. [CrossRef]

38. Wagi, S.; Ahmed, A. Bacillus spp.: Potent microfactories of bacterial IAA. PeerJ 2019, 7, e7258. [CrossRef]

39. Pascale, A.; Proietti, S.; Pantelides, I.S.; Stringlis, I.A. Modulation of the Root Microbiome by Plant Molecules: The Basis for Targeted Disease Suppression and Plant Growth Promotion. Front. Plant. Sci. 2020, 10, 1741. [CrossRef] [PubMed]

40. Shukla, K.P.; Sharma, S.; Singh, N.K.; Singh, V.; Bisht, S.; Kumar, V. Rhizoremediation: A Promising Rhizosphere Technology. Appl. Bioremediation-Act. Passiv. Approaches 2013, 2, 333-352. [CrossRef]

41. Shukla, K.P.; Singh, N.K.; Sharma, S. Bioremediation: Developments, Current Practices and Perspectives. Genet. Eng. Biotechnol. J. 2010, 3. [CrossRef]

42. Jan, M.; Shah, G.; Masood, S.; Iqbal Shinwari, K.; Hameed, R.; Rha, E.S.; Jamil, M. Bacillus Cereus Enhanced Phytoremediation Ability of Rice Seedlings under Cadmium Toxicity. Biomed. Res. Int. 2019, 8134651. [CrossRef] [PubMed]

43. Jamil, M.; Zeb, S.; Anees, M.; Roohi, A.; Ahmed, I.; ur Rehman, S.; Rha, E.S. Role of Bacillus licheniformis in phytoremediation of nickel contaminated soil cultivated with rice. Int. J. Phytoremediation 2014, 16, 554-571. [CrossRef] [PubMed]

44. Peng, H.; Liang, K.; Luo, H.; Huang, H.; Luo, S.; Zhang, A.; Xu, H.; Xu, F. A Bacillus and Lysinibacillus sp. bio-augmented Festuca arundinacea phytoremediation system for the rapid decontamination of chromium influenced soil. Chemosphere 2021, 283, 131186. [CrossRef] [PubMed]

45. Chikere, C.B.; Azubuike, C.C.; Fubara, E.M. Shift in microbial group during remediation by enhanced natural attenuation (RENA) of a crude oil-impacted soil: A case study of Ikarama Community, Bayelsa, Nigeria. 3 Biotech 2017, 152. [CrossRef]

46. Li, S.W.; Huang, Y.X.; Liu, M.Y. Transcriptome profiling reveals the molecular processes for survival of Lysinibacillus fusiformis strain 15-4 in petroleum environments. Ecotoxicol. Environ. Saf. 2020, 192, 110250. [CrossRef] [PubMed]

47. Prittesh, P.; Avnika, P.; Kinjal, P.; Jinal, H.N.; Sakthivel, K.; Amaresan, N. Amelioration effect of salt-tolerant plant growthpromoting bacteria on growth and physiological properties of rice (Oryza sativa) under salt-stressed conditions. Arch. Microbiol. 2020, 202, 2419-2428. [CrossRef] [PubMed]

48. Shen, W.; Yu, X.; Gao, N.; Ota, S.; Shiratori, Y.; Nishizawa, T.; Isobe, K.; He, X.; Senoo, K. Genome Sequence of Arthrobacter sp. UKPF54-2, a Plant Growth-Promoting Rhizobacterial Strain Isolated from Paddy Soil. Microbi. Resour. Announc. 2019, 8 , $\mathrm{e} 01005-19$. [CrossRef]

49. Xu, X.; Xu, M.; Zhao, Q.; Xia, Y.; Chen, C.; Shen, Z. Complete Genome Sequence of Cd(II)-Resistant Arthrobacter sp. PGP41, a Plant Growth-Promoting Bacterium with Potential in Microbe-Assisted Phytoremediation. Curr. Microbiol. 2018, 75, 1231-1239. [CrossRef] [PubMed] 
50. Ali, N.; Dashti, N.; Khanafer, M.; Al-Awadhi, H.; Radwan, S. Bioremediation of soils saturated with spilled crude oil. Sci. Rep. 2020, 10, 1116. [CrossRef]

51. Kim, J.; Kim, S.J.; Kim, S.H.; Moon, Y.J.; Park, S.J.; Kim, S.I.; Kahng, H.Y.; Chung, Y.H. Genome Sequence of Arthrobacter sp. MWB30, Isolated from a Crude Oil-Contaminated Seashore. Genome Announc. 2015, 3, e00013-e00015. [CrossRef]

52. Schippers, A.; Bosecker, K.; Spröer, C.; Schumann, P. Microbacterium oleivorans sp. nov. and Microbacterium hydrocarbonoxydans sp. nov.; novel crude-oil-degrading Gram-positive bacteria. Int. J. Syst. Evol. Microbiol. 2005, 55, 655-660. [CrossRef]

53. Ouertani, R.; Ouertani, A.; Mahjoubi, M.; Bousselmi, Y.; Najjari, A.; Cherif, H.; Chamkhi, A.; Mosbah, A.; Khdhira, H.; Sghaier, H.; et al. New Plant Growth-Promoting, Chromium-Detoxifying Microbacterium Species Isolated From a Tannery Wastewater: Performance and Genomic Insights. Front. Bioen. Biotechnol. 2020, 8, 521. [CrossRef]

54. Singh, T.; Singh, D.K. Rhizospheric Microbacterium sp. P27 Showing Potential of Lindane Degradation and Plant Growth Promoting Traits. Curr. Microbiol. 2019, 76, 888-895. [CrossRef]

55. Zhang, L.; Chen, W.; Jiang, Q.; Fei, Z.; Xiao, M. Genome analysis of plant growth-promoting rhizobacterium Pseudomonas chlororaphis subsp. aurantiaca JD37 and insights from comparasion of genomics with three Pseudomonas strains. Microbiol. Res. 2020, 237, 126483. [CrossRef]

56. Das, D.; Mawlong, G.T.; Sarki, Y.N.; Singh, A.K.; Chikkaputtaiah, C.; Boruah, H.P.D. Transcriptome analysis of crude oil degrading Pseudomonas aeruginosa strains for identification of potential genes involved in crude oil degradation. Gene 2020, 755, 144909. [CrossRef]

57. Wass, T.J.; Syed-Ab-Rahman, S.F.; Carvalhais, L.C.; Ferguson, B.J.; Schenk, P.M. Complete Genome Sequence of Achromobacter spanius UQ283, a Soilborne Isolate Exhibiting Plant Growth-Promoting Properties. Microbiol. Resour. Announc. 2019, 8, e00236-19. [CrossRef]

58. Jiménez-Vázquez, K.R.; García-Cárdenas, E.; Barrera-Ortiz, S.; Ortiz-Castro, R.; Ruiz-Herrera, L.F.; Ramos-Acosta, B.P.; CoriaArellano, J.L.; Sáenz-Mata, J.; López-Bucio, J. The plant beneficial rhizobacterium Achromobacter sp. 5B1 influences root development through auxin signaling and redistribution. Plant. J. 2020, 103, 1639-1654. [CrossRef]

59. Deng, M.C.; Li, J.; Liang, F.R.; Yi, M.; Xu, X.M.; Yuan, J.P.; Peng, J.; Wu, C.F.; Wang, J.H. Isolation and characterization of a novel hydrocarbon-degrading bacterium Achromobacter sp. HZ01 from the crude oil-contaminated seawater at the Daya Bay, southern China. Mar. Pollut. Bull. 2014, 83, 79-86. [CrossRef]

60. Deng, Z.; Jiang, Y.; Chen, K.; Li, J.; Zheng, C.; Gao, F.; Liu, X. One Biosurfactant-Producing Bacteria Achromobacter sp. A-8 and Its Potential Use in Microbial Enhanced Oil Recovery and Bioremediation. Front. Microbiol. 2020, 11, 247. [CrossRef] 